\title{
WestVirginiaUniversity
}

THE RESEARCH REPOSITORY @ WVU

Graduate Theses, Dissertations, and Problem Reports

2000

\section{Breastfeeding personal efficacy beliefs of women university students}

Ann Pollard Cleveland

West Virginia University

Follow this and additional works at: https://researchrepository.wvu.edu/etd

\section{Recommended Citation}

Cleveland, Ann Pollard, "Breastfeeding personal efficacy beliefs of women university students" (2000). Graduate Theses, Dissertations, and Problem Reports. 2319.

https://researchrepository.wvu.edu/etd/2319

This Dissertation is protected by copyright and/or related rights. It has been brought to you by the The Research Repository @ WVU with permission from the rights-holder(s). You are free to use this Dissertation in any way that is permitted by the copyright and related rights legislation that applies to your use. For other uses you must obtain permission from the rights-holder(s) directly, unless additional rights are indicated by a Creative Commons license in the record and/ or on the work itself. This Dissertation has been accepted for inclusion in WVU Graduate Theses, Dissertations, and Problem Reports collection by an authorized administrator of The Research Repository @ WVU.

For more information, please contact researchrepository@mail.wvu.edu. 


\title{
Breastfeeding Personal Efficacy Beliefs of Women University Students
}

\author{
Ann Pollard Cleveland \\ Dissertation submitted to the \\ College of Human Resources and Education \\ At West Virginia University \\ In Partial fullfilment of the requirements \\ For the degree of \\ Doctor of Education \\ In \\ Educational Psychology \\ Anne Nardi, $\mathrm{PhD}$, Chair \\ Rogers MacAvoy, $\mathrm{PhD}$ \\ Richard Walls, $\mathrm{PhD}$ \\ Van Dempsey, $\mathrm{PhD}$ \\ Dorothy M. Johnson, Ed.D \\ Department of Advanced Educational Studies \\ Morgantown, West Virginia \\ 2000
}

Keyword: Breastfeeding, Self-Efficacy 


\begin{abstract}
Breastfeeding Personal Efficacy Beliefs of Women University Students
\end{abstract}

\author{
Ann Pollard Cleveland
}

Many women do not initiate breastfeeding although breastfeeding promotes their baby's health. Three reasons why women do not breastfeed are women's mental organization, cultural beliefs about breastfeeding, and women's breastfeeding personal efficacy beliefs. The conceptual framework for personal efficacy beliefs is Bandura's social-cognitive theory $(1992,1995,1997)$. This dissertation used a new research instrument to examine women university students' breastfeeding personal efficacy beliefs. The instrument was tested by mail survey techniques that resulted in a $70.6 \%$ respondent rate. University women's personal efficacy beliefs about breastfeeding factored into five factor subscales. In order of magnitude, the personal efficacy belief factors were "How," "When," Who," "Why," and "What." Initial evidence of satisfactory reliability and validity of the Breastfeeding Personal Efficacy Beliefs Inventory was established. The relationship of academic rank to personal efficacy beliefs about breastfeeding was weakly supported. The findings were an initial empirical description of the development of breastfeeding personal efficacy beliefs in women university students. Interventions for symbolic learning can now be designed from these findings and tested to increase breastfeeding personal efficacy beliefs. Symbolic learning is the one influence on personal efficacy beliefs that does not require actual breastfeeding. 


\section{Acknowledgements}

I sincerely thank my chair and the members of my doctoral committee for their time, energy and encouragement during the process of my dissertation. In addition, I thank James Paterson, $\mathrm{PhD}$, for his support of my initial doctoral studies. Finally, I thank my husband and son for being patient and kind. 


\section{Table of Contents}

Breastfeeding Personal Efficacy Beliefs of Women University Students ...................... i

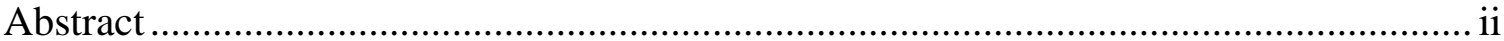

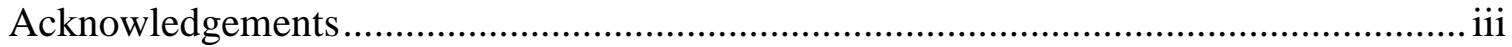

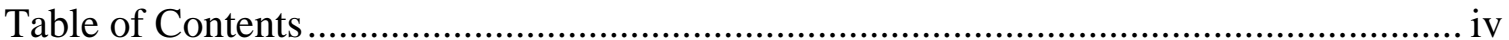

List of Tables

Chapter 1

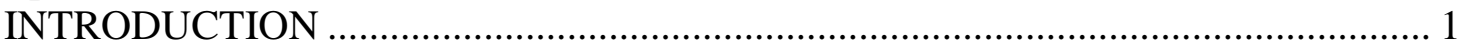

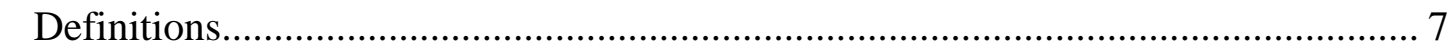

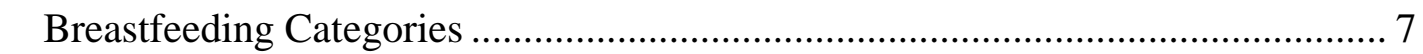

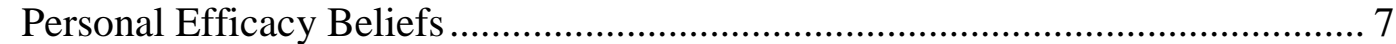

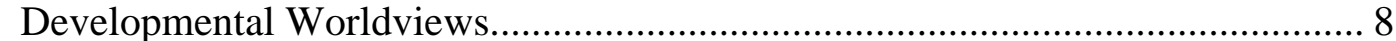

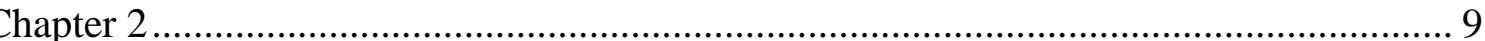

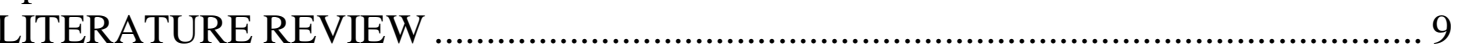

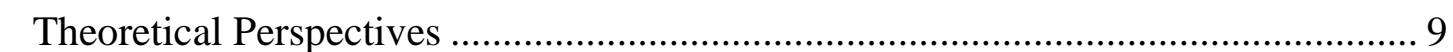

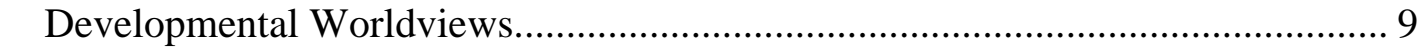

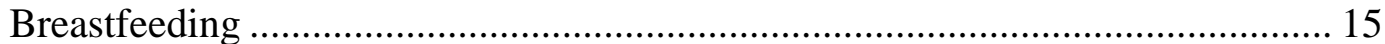

Breastfeeding promotion.................................................................. 15

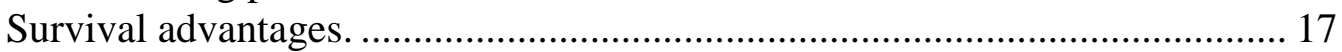

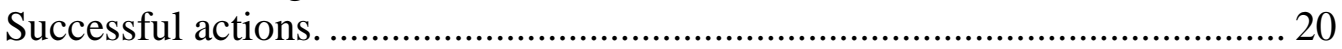

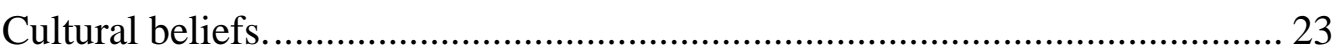

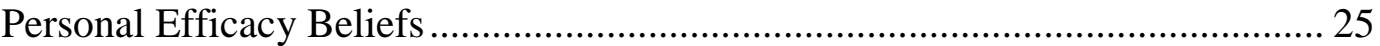

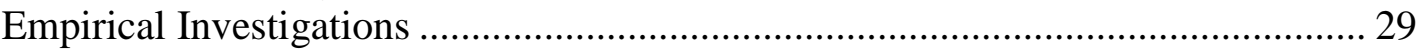

Statement of the Problem ................................................................................ 44

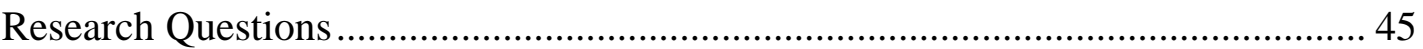

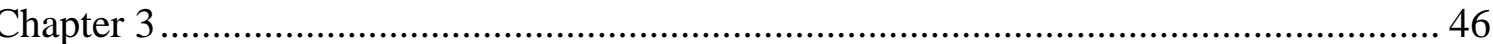

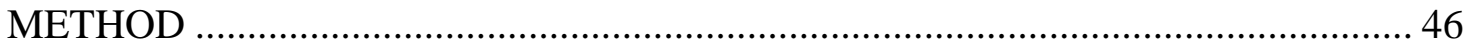

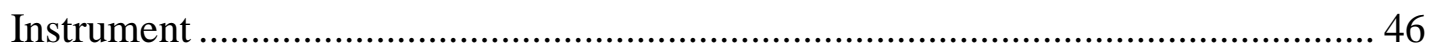

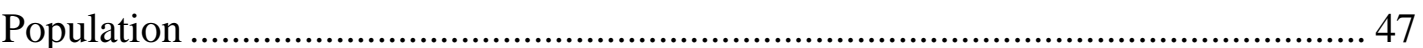

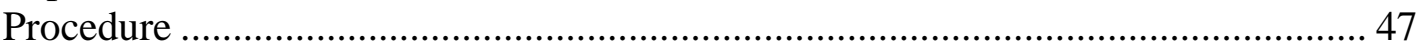

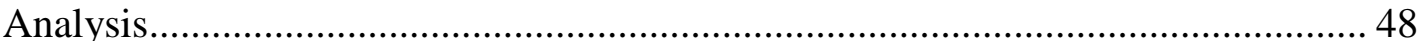

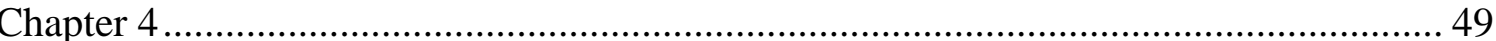

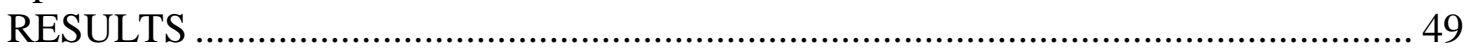

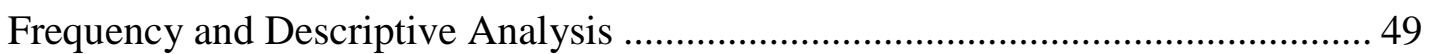

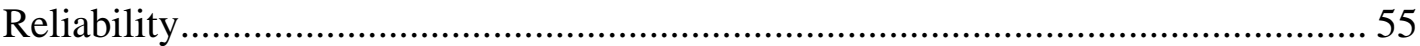

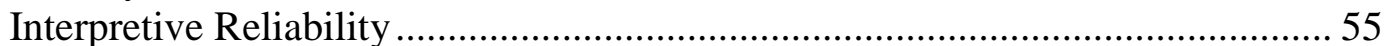

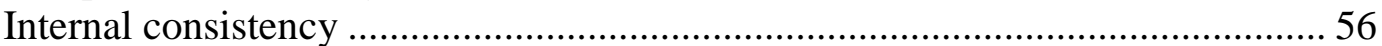

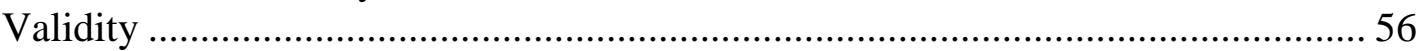

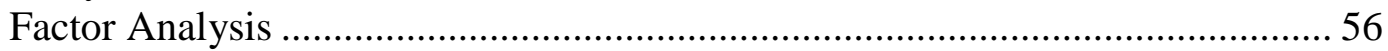

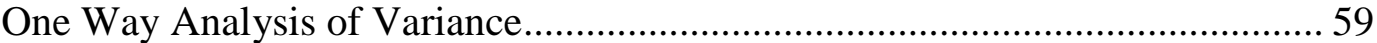

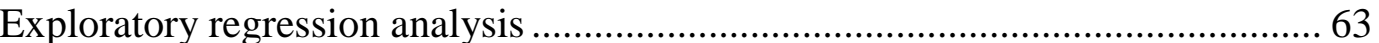

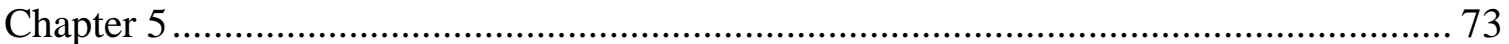

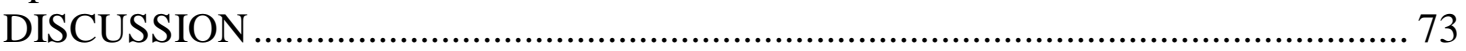

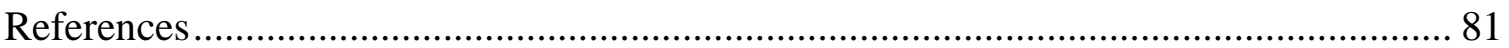

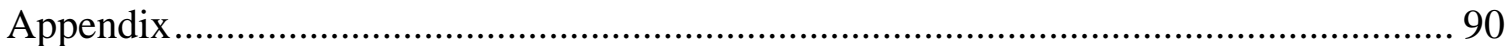




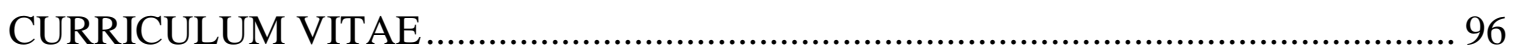




\section{List of Tables}

Page

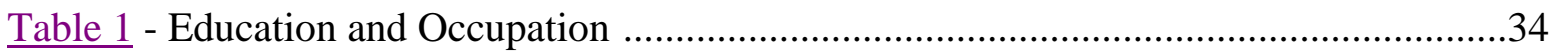

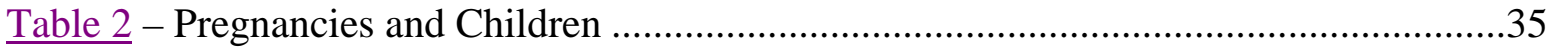

Table 3 - Mothers' Breastfeeding Satisfaction and Experience .......................................36

Table 4 - Significant Differences in Scores of Mothers Grouped by Breastfeeding

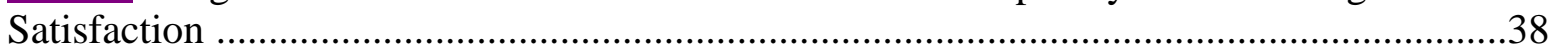

Table 5- Significant Difference in Scores of Younger Childless Women and Satisfied

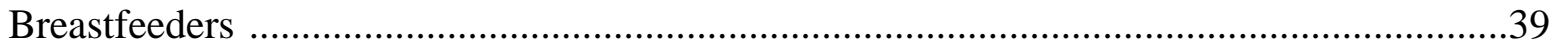

Table 6-Comments, Omissions, and Suggestions of Participants ...................................40

Table 7 - Summary of Participants' Academic Experience ..............................................50

Table 8 - Summary of Participants' Pregnancy and Breastfeeding Experiences .................52

Table 9 - Means of Participants' Breastfeeding Personal Efficacy Beliefs ..........................53

Table 10- Factor Analysis of Breastfeeding Personal Efficacy Beliefs..............................58

Table 11 - Analysis of Variance for Inventory Scores of Mothers and Non-Mothers .........60

Table 12 - Analysis of Variance for Inventory Scores of Breastfeeders and Non-

Breastfeeders (Mothers and Childless) ......................................................................61

Table 13-Analysis of Variance for Inventory Scores of Participants Grouped By

Academic Rank

Table 14-Summary of Stepwise Regression for Independent Variables Predicting

Inventory Score

Table 15-Summary of Stepwise Regression for Independent Variables Predicting the

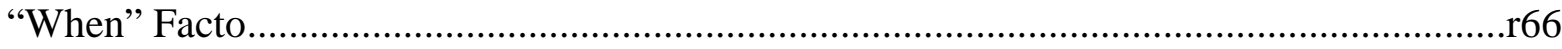

Table 16-Summary of Stepwise Regression for Independent Variables Predicting the

"How" Factor

Table 17-Summary of Stepwise Regression for Independent Variables Predicting the

"Who" Factor.

Table 18-Summary of Stepwise Regression for Independent Variables Predicting the

"What" Factor

Table 19-Summary of Stepwise Regression for Independent Variables Predicting the "Why" Factor 


\section{Chapter 1 INTRODUCTION}

The health of children improves significantly when babies are breastfed (Duffy, Faden, Wasielewski, Wolf, \& Krystofik, 1997; Lawrence, 1994; Riordan \& Auerbach, 1999). Both species-specific mothers' milk and adult protection during the growing years are nature's heritage for children (Riordan \& Auerbach, 1999). Around the world, cultures that use more substitutes for mother's milk have higher infant mortality rates (Cunningham, 1995; Dettwyler, 1995). As a result, the World Health Organization (WHO) recommends breastfeeding babies for two years (1989).

Mother's milk-substitutes originated for children who were either orphaned or separated from their families (Cunningham, 1995; Dettwyler, 1995). But, at the end of the twentieth century, milk-substitutes had become a worldwide economic force. During each day of 1995, 22 million dollars was spent on these products around the world (Baumslag \& Micheals, 1995). In 1995, Ryan reported that $60 \%$ of babies born in the United States drank some mother's milk after birth. This percentage dropped rapidly during the weeks following birth. By six-months of age, only $21 \%$ of babies drank some mother's milk (Ryan, 1997).

Cultural beliefs are responsible for lower breastfeeding rates (Baumslag \& Micheals, 1995; Dettwyler, 1995). Gaskin gave the name "nipplephobia" to the cultural undermining of breastfeeding (Friedman, 1998). She believed that nipplephobia caused irrational behavior and rudeness to breastfeeding mothers who were feeding their babies the best nourishment possible. Gaskin, a midwife and editor of Birth Gazette, said, "Fortunately, there is hope!" She believed that nipplephobia can be cured by "visual stimulation overload" or "watching great numbers of women breastfeed their children in public places" (p.26). She encouraged support of public 
breastfeeding, showing the Norwegian video "Breast is Best" to everyone possible, and displaying (and discussing) breastfeeding art at home and at work.

Health professionals are subject to nipplephobia. Surveys revealed many gave inaccurate and inappropriate breastfeeding advice and expected breastfeeding failure (Coreil, Bryant, Westover, \& Baily, 1995; Schanler, O’Connor, \& Lawrence, 1999). Izatt (1997) reported only $23 \%$ of 111 women were counseled about breastfeeding by their obstetricians. Sable and Patton (1998) reported that only $37 \%$ women in a large national study were advised to consider breastfeeding by their health care providers. A survey of physicians found they lacked confidence that women were capable of breastfeeding one or two babies (Hattori \& Hattori, 1999; Mozingo, 1996). In addition, health professionals lacked effective breastfeeding promotion skills (Burglehaus, Smith, Sheps, \& Green, 1997).

Breastfeeding is health promotion behavior. Health promotion behavior can be encouraged in communities or with specific individuals (Bandura, 1992, 1995, 1997; Pender, 1996). Community methods are planned campaigns that increase aggregate behavior. Individual methods influence people one by one. According to Bandura's social learning theory (1992, 1995, 1997), community and individual methods of promoting healthy behavior are effective when they use personal efficacy beliefs.

Personal efficacy beliefs are defined as judgements about one's likelihood of success in completing a specific behavior under different circumstances (Bandura, 1992, 1995, 1997). Personal efficacy beliefs include actions, motivation, feelings, and thoughts about behavior (Bandura, 1992,1995, 1997). Both initiation and perseverance of behavior are predicted by personal efficacy beliefs (Bandura, 1992,1995, 1997; Pender, 1996). Four factors influence personal efficacy beliefs. The factors are, in decreasing order of influence, successful practice, 
role modeling, verbal persuasion about personal efficacy, and comfortable feelings during performance (Bandura,1992, 1995, 1997). The childhood story, The Little Engine That Could, by Watty Piper (1930) exemplifies the effect of a positive sense of efficacy.

Both, nipplephobia and personal efficacy beliefs offer some explanation of women's breastfeeding behavior. Human developmental theory has additional explanations because age, experience, and culture make a difference in breastfeeding behavior (Baunslag \& Micheals, 1995; Dettwyler, 1995). The age that women make breastfeeding decisions is surprisingly young. Most women studied by Oxby (1994) had made a breastfeeding decision early in their childbearing years, many before they became pregnant and a few early in their pregnancies. In addition, many adolescent girls reported having already made a breastfeeding decision (Purtell, 1994; Van Poppel \& Estok, 1994). Other surveys have found that older mothers and women who lived the western region of the U.S., who were not poor, who did not smoke, and who had more education, were more likely to breastfeed (Lawrence, 1994; Scott, \& Binns, 1999; Shepherd, Power, \& Carter, 1998).

The experience of breastfeeding impacts women. Lockin (1995) found low-income women described themselves as empowered by breastfeeding. The mothers in her study felt important to their babies and proud of conquering cultural challenges to breastfeeding. Social support, especially from the baby's father, was important to success for some women (Humphreys, Thompson, \& Miner, 1998; Kessler, Gielen, Diener-West, \& Paige, 1995). Grandmothers greatly influence health practices of their family members in West Virginia (Purnell \& Counts, 1998).

Age, experience, and culture are important in Kegan's $(1982,1994)$ constructivist, developmental theory. He described five developmental changes or worldviews that can occur 
over a lifetime. Kegan's names his first worldview magical thinking. This describes the young child's thoughts that are free from the restrictions of logic.

Older children and adolescents "expand" their thinking to Kegan's second worldview. Logical thinking develops as thoughts are organized by durable categories. But, personal needs and preferences heavily influence the logic of this age. The third worldview is the adult's initial worldview. Kegan described his third worldview as traditional adult thinking. With this worldview, thinking is guided by the tradition of the women's childhood community. Around the world, the majority of women keep their traditional worldview all of their lives (Kegan, 1982, 1994).

However, in certain circumstances, adult women expand their worldview to selfregulated thinking (Kegan, 1982,1994). Kegan stated that this expansion takes at least four years. During this expansion, the woman first questions her traditional worldview, and then, slowly, establishes self-regulated thinking (1994). Kegan believed that Women's Ways of Knowing (Belenky, Clinchy, Goldberger, \& Tarule, 1986) demonstrated the process of self-regulated worldview expansion. Kegan has found that self-regulated thinking is not accomplished before the mid-twenties. Often college fostered this expansion (Kegan, Marienau, 1995; Taylor \& Marienau, 1995) A few self- regulated women expand their worldview further after age forty (Kegan, 1982, 1994). With Kegan's fifth worldview, women realize both paradoxes and complex inter-connections across systems. They seek experiences opposite to those they experienced previously (Kegan, 1982, 1994).

The expansion of developmental worldview in relation to breastfeeding might progress like this. The adolescent says, "For me, breastfeeding is like this." The traditional woman says, "Mothers like me feed our babies this way." The self-regulated woman says, "I can behave 
differently if I decide it is best for my baby and me." And, finally, the interconnected woman says, "We are all part of a bigger picture that influences our health and behavior."

The author believes that breastfeeding promotion needs two efforts. The first effort is encouraging perseverance of breastfeeding. Several researchers have been studying perseverance (Chezem, Friesen, Montgomery, Fortman, \& Clark, 1998; Morrow, Guerrero, Shults, Calva, Lutter, Bravo, Ruiz-Palacios, Morrow, \& Butterfoss, 1999; O’Campo, Faden, Gielen, \& Wang, 1992). The second effort is increasing initiation of breastfeeding. Research with minority populations has demonstrated some intensive methods that increase their breastfeeding initiation (Long, Funk-Archuleta, Geiger, Mozar \& Heins, 1995; Ryan, 1997; Zimmerman, 1999).

Because of current theory about developmental worldviews, women interested in university education might initiate breastfeeding with lesser amounts of intervention. If health professionals can increase university women's initiation of breastfeeding, the change in breastfeeding rates might be more dramatic than the change possible with non-university women. Increasing the number of breastfeeding women is important so that Gaskins' cure for nipplephobia, "watching great numbers of women breastfeed their children in public places," can occur, among other reasons.

Recently, this author developed a research instrument (Cleveland, 1999) that measured personal efficacy beliefs about breastfeeding. It utilized both expert breastfeeding knowledge and personal efficacy belief theory and was piloted with a small sample of women, aged 18 to 81 years, selected by convenience. To explain the findings, the women participants were grouped according to developmental worldviews. The author revised the inventory slightly after the pilot for clarity and completeness of items. 
The initial inventory was successful in revealing differences in breastfeeding personal efficacy beliefs among groups of women within the sample. Two groups of women, younger childless ones and mothers who never breastfed or breastfed briefly and reported low breastfeeding satisfaction, were significantly different in their personal efficacy beliefs from a third group, mothers who breastfed for longer duration and reported high breastfeeding satisfaction. All the younger childless women were sophomore college students. The college sophomores differed in percent of confidence about breastfeeding in the presence of others, feeling attractive while breastfeeding, ability to make enough milk, and learning technical aspects of breastfeeding from the mothers who breastfed for longer duration and reported high breastfeeding satisfaction (Cleveland, 1999).

The purpose of this dissertation was to describe West Virginia University women's personal efficacy beliefs about breastfeeding with the revised inventory using statistically appropriate sampling methods. After the dissertation, the author can use the personal efficacy belief findings to develop interventions, particularly verbally persuasive statements. If health professionals have interventions that change women's breastfeeding personal efficacy beliefs, breastfeeding rates could be increased.

Specifically, this dissertation investigated developmental worldview influences on women's breastfeeding personal efficacy beliefs. The major focus of the dissertation was to determine whether academic progress, as indicated by academic rank, and as measured by number of college credits earned by university women, correlated to their breastfeeding personal efficacy beliefs. University women are of interest to the author because they tend to be younger women. Most women consider infant feeding possibilities early in their childbearing years. Since worldview expansion often occurs during the college years, university women should reflect the 
various worldviews of young women today. In addition, follow-up study of whether the revised inventory is predictive of the women's future breastfeeding behavior could occur using alumni services.

\section{$\underline{\text { Breastfeeding Categories }}$}

\section{Definitions}

Labbok and Krosovec developed definitions of human lactation variations in 1990 for the purpose of consistency in research. They listed three major categories or percentage ranges of mother's milk in the diet of the baby. These amounts of mother's milk were full, partial and token. Full breastfeeding included exclusive or almost exclusive use of breast milk for nutrition. Partial breastfeeding had three sub-categories: high, which was more that $80 \%$ of feeds: medium which was $79 \%$ to $20 \%$; and low which was less than $20 \%$. Token breastfeeding involved "insignificant caloric contribution" (p.226). In addition to amount of babies' diet, breastfeeding duration has been measured in lengths of time. Also, breastfeeding has been qualified by maternal reported satisfaction level, such as low, medium or high.

\section{$\underline{\text { Personal Efficacy Beliefs }}$}

Personal efficacy beliefs are judgements about one's likelihood of success in completing specific behavior under different circumstances (Bandura, 1992, 1995, 1997). They have been central to the social-cognitive theory developed by Bandura of Stanford University. In human endeavors it has been effective to have a "can do" (Schwarzer, 1992, p. ix) attitude. Personal efficacy beliefs are specific to behavior and not global in nature. Other names for personal efficacy beliefs are perceived self-efficacy and self-efficacy beliefs. For the purposes of this dissertation, 27 personal efficacy beliefs about breastfeeding were identified from the advice of experts about breastfeeding (Lawrence, 1994; Riordan \& Auerback, 1999) and breastfeeding mothers. Each belief variable will be measured individually in terms of percent of confidence. 


\section{$\underline{\text { Developmental Worldviews }}$}

Developmental worldviews reflect mental organization and affect one's total "emotional, cognitive, interpersonal, and intrapersonal experiencing" (Kegan, 1994, p. 7). According to Kegan's constructivist-developmental theory, worldviews expand at least 3 times. These expansions are to magical thought in early childhood, to logical thought influenced by personal needs and preferences during the adolescent years, and to traditional adult thinking at the end of adolescence. Adults might expand their worldviews again, to a self-regulated worldview and to an inter-connected worldview later in life $(1982,1994,1998)$. Several years are necessary for each worldview expansion. According to Kegan, college often results in a worldview expansion from traditional adult thought to self-regulated thought. 


\section{Chapter 2 LITERATURE REVIEW}

Current knowledge about developmental worldviews, breastfeeding, and personal efficacy beliefs is reviewed in this chapter. Recent literature concerning theoretical perspectives is presented. Then, empirical studies about personal efficacy beliefs and breastfeeding personal efficacy beliefs are reviewed. A statement of the problem and the research question of this dissertation conclude the chapter.

\section{Developmental Worldviews}

\section{Theoretical Perspectives}

Because women who breastfeed in the United States differ in age, in educational level, in social class, and in social support from those who have not, adult developmental theory about women has importance to breastfeeding personal efficacy beliefs. Kegan's cognitive, developmental theory (Kegan, 1982, 1994; Kegan, Lahey, \& Souvaine, 1998) delineated worldviews that change over a lifetime. According to this theory, people, around the world, have at least three developmental worldviews during their lifetimes. One occurs during childhood, a second occurs during adolescence, and a third occurs during adulthood. When age, culture, and experience support adult development, two more complex adult worldviews are possible.

Kegan's graduate studies were with Kohlberg at Harvard University during the 1970's. Gilligan was one of his classmates (Kegan et al., 1998). Kegan developed his constructivist, developmental theory from Piaget's cognitive theory, Kohlberg's theory of moral reasoning, and Loevinger's conception of ego development. Loevinger wrote that there "exists in personality, at any given time, a holism or 'central tendency' in one's meaning - organizing” (p.40). Loevinger identified stages of ego development. Kegan and his colleagues were concerned with delineating its underlying structures. 
Kegan (1994) explained individual mental organization as "the relationship between two fascinating phenomena, one psychological and one cultural (p. 9)." The psychological phenomena was the evolution of consciousness, "the personal unfolding of ways of organizing experience that are not simply replaced as we grow but subsumed into more complex systems of mind" (p. 9). Kegan's equally important “cultural phenomenon is the "hidden curriculum"'(p. 9) of the mind. Kegan's idea was that, to the common definition of culture, we need to add "the claims or demands the culture makes on the minds of its constituents" (p. 9). Kegan's constructivist, developmental approach incorporated the styles of knowing of Belenky, Clinchy, Goldberger, and Tarule (1986), Briggs-Myers, (1980), Gilligan, (1982), and Kolb, (1980). Kegan's developmental approach incorporated the theories of Elkind, (1974, 1976, 1981, 1987), Erikson (1963), Freud (1969), Horney (1950), Jung (1965), Kohlberg (1976), Mitchell, (1977), Perry, (1968), Piaget (1966, 1968), and Sullivan, (1953).

Children experience "magical thinking," the initial worldview (Kegan, 1982, 1994), from two through six years of age. With magical thinking, sensory and motor experiences are incorporated into a structure that allows single point, atomistic ideas. Perceptions, fantasy, impulses, and a limited, personal point of view, are typical during early childhood. Immediate perceptions explain the cause of events to the young child. "Expansion," or developmental change, to "logical thinking" occurs during the years of seven and eight according to Kegan.

Children aged nine through the late teen years organize mentally with durable, nonchangeable categories rather than the magically changing categories of the younger child (Kegan, 1982, 1994). Key ideas of the second worldview include concrete and logical thinking with the use of actuality, data, cause, and effect. Young people understand the concepts of roles and simple reciprocity (tit for tat). Needs, preferences, and self-concept, are major characteristics 
of the second worldview. For better teenage health, Kegan recommended that society promote a culture that, both, meet teenagers' needs and promote their health. Kegan wrote that, if both were accomplished, the consequences of needs-oriented logical thinking would become less dangerous.

Practicing abstract thinking during adolescence, as described by Piaget, allows expansion to the first adult worldview (Kegan, 1982, 1994). Traditions dominate Kegan's $(1982,1994)$ third worldview. He stated,

Nearly twenty years of living may go into the gradual evolution of a mental capacity that enables one to think abstractly, identify a complex internal psychological life, orient to the welfare of a human relationship, construct values and ideas self-consciously know as such, and subordinate one's own interest on behalf of one's greater loyalty to maintaining bonds of friendship, or team or group participation. (1994, p.75)

With traditional adult thinking, people accept the traditions of their family and their specific community. Key ideas of "traditional thinking" include ideals, values, inference, generalization, subjectivity, mutual reciprocity, and understanding abstractions (Kegan, 1982, 1994).

The fourth worldview is called "modern thinking" by Kegan (1982, 1994). It begins after age 20. While earlier expansions are closely related to chronological age, this expansion happens when individual and cultural readiness factors are present. The person gradually expands from community-controlled traditions to personal internal regulation. Self-regulation, self-formation, identity, autonomy, individualization, and understanding abstract systems, are key ideas of the fourth worldview. Some people live a traditional "life-style" with a fourth level worldview, but they, personally, select that tradition over others (1994). Often, college and graduate schools 
promote the expansion to modern thinking, but not automatically. Both individual factors and some educational programs delay expansion (Kegan, 1982, 1994).

According to Kegan $(1982,1994)$ expansion between traditional adult thinking and modern thinking is at least a four-year process. First, the traditional worldview is reflected upon, and then, self-regulation is slowly constructed. Finally, self-regulation becomes the person's dominant worldview. Some educators (Droegkamp \& Taylor, 1995; Marienau, 1995; Taylor \& Marienau, 1995) have designed educational tasks, called "bridges," that are accomplished either within the current worldview or during expansion. The educator hopes to stimulate expansion, but, if the student is not ready to change, the bridge is completed satisfactorily within the student's current worldview (Kegan).

Kegan (1994) related his developmental worldviews to Belenky et al.'s (1986) Women's Ways of Knowing. These authors named five different ways of knowing, derived from their qualitative research, which women could experience during their early adult years. Buczynski designed a research instrument in 1993 that lists thoughts characteristic of Women's Ways of Knowing. Two of Buczynski’s (1993) received knowledge items were, "I find myself looking to others for knowledge," and "I think that learning is retaining and returning what authorities tell me” (p.199). For Kegan, traditional adult thinking was reflected in Belenky et al.'s (1986) “received knowledge” way of knowing. Kegan wrote that Belenky et al.'s (1986) “subjective” way of knowing was the start of expansion from traditional thinking to self-regulated thinking. Thoughts characteristic of subjective thinking were, "In the past I have never had an identity of my own," and, "Sometimes I feel like I am on a speeding freight train and have no control over the events in my life." (Buczynski, 1993, p. 199). Kegan (1994) described these thoughts as demonstrating the coming apart of the traditional worldview. Once worldview expansion began, 
Kegan $(1982,1994)$ believed that it was likely to continue. Change according to pattern has been the essence of human developmental theories.

Kegan's $(1982,1994)$ fifth worldview, called “post-modern," occurs after forty years of age and, again, involves a period of expansion. People with the fifth worldview consider paradox, contradiction and views previously opposite to their own. Kegan described thinking that was trans-system, trans-complex and trans-ideology. People with post-modern thinking are interested in what they have not been, rather than what they have been. Although only small numbers of people currently have reached the fifth worldview, Kegan speculated more people would achieve post-modern thinking as life expectancy increases.

Since post-modern thinkers view the world as interconnected and related, they are likely to impose their worldview on those younger than themselves (Kegan, 1982, 1994). Kegan advised being careful about being a "companion" on the wrong “journey." Readiness, both personal and cultural, was necessary for worldview expansion. Women can be encouraged by others to expand their worldview, but they could not be hurried or forced (Kegan, 1982, 1994).

Kegan (1982, 1994) and Kegan, Lahey and Souvaine (1998) described a qualitative interview technique by which they determined developmental worldviews. The research interview, called “The Subject-Object Interview," was conducted in the style of Piaget. Personal verbal descriptions revealed the subject's underlying system of thinking. Open-ended questions were asked about recent occasions of being angry, anxious or nervous, of experiencing success, of taking a strong stand or conviction, of being sad, torn, moved or touched, of a personal loss, and of an important change (Bar-Yam, 1991). One question was, "Can you tell me about a recent experience when you were quite angry about something?" (Kegan et al., 1998). The subject's answers were analyzed qualitatively for worldview orientation (Bar-Yam, 1991). 
In their book, Knowledge, Difference and Power, (1996) Goldberger, Tarule, Clinchy and Belenky considered the effects of their previous work, Women's Ways of Knowing (1986). Ann Stanton, a contributor, wrote:

The whole point of a developmental theory is not to pin the individual rigidly into a category but to locate her/him with reference to a sequence, providing a way to conceptualize where the student is and in what directions she might be ready to move. (p.40)

Some breastfeeding studies have revealed worldview development. If women have demonstrated received knowledge (Belenky et al.'s, 1986), and families and communities have not supported breast feeding, then continuous support and guidance from other trusted people have been necessary for successful breastfeeding (Bove, 1996). Professional lactation counselors (Coreil et al., 1994), peer counselors, and support groups (Long, Funk-Archuleta, Geiger, Mozar, \& Heins, 1995) have provided support and guidance. Other professional guidance has not been as successful. Some people promoting breastfeeding might be post-modern thinkers (Kegan, 1982, 1994). Post-modern thinkers might not respect the needs of younger women to be given accurate information and to make decisions for their own families.

This author believes that the empowerment low-income women felt from breastfeeding in Locklin's 1995 qualitative study demonstrated expansion from traditional toward self-regulated worldviews. Since breastfeeding had many cultural constraints (Baumslag \& Michels, 1995; Coreil et al., 1995; Dettwyler, 1995; Lawrence, 1994; Locklin, 1995), the challenge of breastfeeding stimulated worldview expansion. Another study (Allison, 1994) of differences in Afro-American mothers revealed that breastfeeding mothers felt more internally motivated, while the mother's milk substitute users felt more externally motivated. Other survey data have 
shown women who were more likely to have expanded worldviews, including older, more educated and non-smoking women, have higher breastfeeding initiation and perseverance rates, (Lawrence, 1994; Scott, \& Binns, 1999; Shepherd, Power, \& Carter, 1998).

\section{Breastfeeding}

Breastfeeding promotion.

Breastfeeding rates in the United States declined steadily during most of the twentieth century. The rates reached their lowest point during 1984 when breastfeeding was initiated by 52 $\%$ of women, and only $17 \%$ of women were still breastfeeding six-months after giving birth (Ryan, 1991). In an effort to reverse the trend away from breastfeeding, the U. S. Surgeon General organized a joint meeting of many health-related professional organizations in 1984 . These organizations declared breastfeeding the feeding method of choice for babies (Lawrence, 1994). Since 1992, both the American Academy of Pediatrics and the American College of Obstetricians and Gynecologists have recommended breastfeeding for one year.

The U.S. Government set breastfeeding goals in Healthy People 1990 (1980) and Healthy People 2000 (1990). These goals were for $75 \%$ of babies to breastfeed initially, and $50 \%$ of babies to be breastfeeding at 6 months of age. Initiatives in the Women's, Infant's, and Children (WIC) Program established support for the Healthy People 2000 breastfeeding goals. Increased funding was available for staff training and peer counseling, visibility of mother's milk substitutes was curtailed in WIC clinics, and a greater variety of food was available to women who persevere at breastfeeding (Riordan \& Auerback, 1999). Since the late 1980's, increased numbers of poorer and less educated women were breastfeeding in the United States (Ryan, 1997). Worldwide, breastfeeding promotion was part of the child health promotion program of the World Health Organization (WHO). Their "Ten Steps to Successful Breastfeeding" and 
"Code for Marketing Breast-Milk Substitutes" guided the design of child health promotion interventions. WHO endorsed "baby friendly" hospitals around the world (1989). "Baby friendly" hospitals provided evidence to an external review board that they practiced the "Ten Steps to Successful Breastfeeding” (Kovach, 1997).

Strategies promoting breastfeeding have developed in the United States. Childbirth education classes with discussion of infant feeding methods were widely available. Support from Le Leche League, the breastfeeding mothers support group, was essential to many women who breastfed successfully. Membership is inexpensive, and scholarships are available (Riordan \& Auerbach, 1999). Independent of La Leche league, the training of "doulas" has occurred across the country. Doulas are knowledgeable and supportive women, who are available to new mothers for many kinds of support, including breastfeeding (Rapheal, 1976). In 1995, breastfeeding rates increased to $60 \%$ for initiation and $21 \%$ for six-month duration of breastfeeding (Ryan, 1997). The federal Best Start Breastfeeding Promotion Campaign, currently underway, has been expected to increase public awareness of the benefits of breastfeeding (Schanler et al., 1999). Recently, a United States Breastfeeding Committee was organized to plan and submit a strategic plan to the U. S. Department of Health and Human Services (Spangler, 1999).

Bandura $(1992,1995,1997)$ recommended the use of personal efficacy beliefs to plan effective health promotion interventions on both the individual and community levels. Research instrument development in personal efficacy beliefs requires expert knowledge of the actions, motivation, feelings and thinking about the health behavior being studied (Bandura, 1992,1995, 1997). Women's breastfeeding actions are techniques that enhance successful breastfeeding. Women's breastfeeding motivation relates to cultural beliefs and to verbal persuasion by other people. Feelings of women include physical and psychological comfort during breastfeeding. 
Finally, thinking about breastfeeding includes perceived barriers to and perceived advantages of breastfeeding.

Previously, the author developed the Personal Efficacy Beliefs about Breastfeeding Inventory (PEBBI), guided by three threads from the immense breastfeeding literature. The three threads incorporated women's actions, motivation, feelings, and thinking about breastfeeding. The threads were breastfeeding's survival advantages, successful breastfeeding actions, and cultural beliefs that undermine breastfeeding.

Survival advantages.

During the twentieth century, multiple research disciplines have contributed to knowledge about breastfeeding's survival advantages and successful breastfeeding actions. Lawrence (1994), a pediatrician, and two nurses, Riordan and Auerbach (1999) have written internationally acclaimed textbooks that are empirically based, well-referenced, and available in recent editions. Lawrence has been the director of the Breastfeeding Center at Rochester University. The Riordan and Auerbach textbook has been the basis for the International Lactation Consultant Board Certification examination. Lawrence, Riordan, and Auerbach delineated some of the breastfeeding survival advantages and successful advice included in this section. In addition, recent studies concerning survival advantages and successful advice are referenced.

Human survival has been promoted by human lactation (Lawrence, 1994; Riordan \& Auerbach, 1999). Breastfeeding babies have nutritional, immunological, cognitive, and familial advantages. Both human milk biochemistry and human biology have produced evidence of the nutritional advantages of breastfeeding. Human babies double their weight in 4 to 6 months while other mammals double their weight in a shorter time. Proteins, fat, carbohydrates, 
vitamins, and minerals in mother's milk varied from the milk of other mammals and from mother's milk- substitutes. Cow's milk is the basis for most substitute milk but calves grow much faster than humans grow. Babies fed substitute milk were heavier as children than breastfed babies were (Dewy, 1995; Fawzi, 1997) and have higher blood pressure as children (Wilson, Forsyth, Greene, Irvine, Hau \& Howie, 1998). The composition of substitute milks is the same, but the composition of mother's milk changes "over time of day and as time goes by" (Lawrence, 1994, p. 91). These changes match the changing physiology of the gut of the growing baby. Although some breastfeeding babies have colic, they have less of it than babies fed substitute milk did. In summary, breast milk provides the baby with better nutrition and better digestion.

Human milk has immunologic advantages (Lawrence, 1994; Riordan \& Auerbach, 1999). Colostrum, transitional milk, and mature mother's milk contain, “various immunoglobulins (IG), especially IgA, macrophages, granulocytes, T- and B-cell lymphocytes, and other factors that inhibit bacterial growth" (Wong, 1999, p. 337). When a mother is exposed to an infectious agent, she gives her baby passive immunity to the infectious agent through breastfeeding. Breastfed babies have fewer and less severe infections (Dewey, Heinig, Nommsen-Rivers, 1995; Duncan, 1993). This advantage, as well as lowered blood pressure and decreased body fat, continues after breastfeeding is discontinued if breastfeeding's duration is several months (Wilson, Forsyth, Greene, Irvine, Hau \& Howie, 1998). Breastfed babies in day care in the United States are sick less often than other babies (Duffy, Faden, Wasielewski, Wolf \& Krystofik, 1997). Their mothers, also, miss less work (Riordan, 1997). Community interventions to increase breastfeeding reduced infant illness at the community level (Wright, Bauer, Naylor, Sutcliffe, \& Clark, 1998). Babies fed mother's milk-substitutes have higher health care costs from respiratory 
illness, otitis media, meningitis and gastrointestinal illness (Ball \& Wright, 1999; Silfverdal, Bodin \& Olcen, 1999). They, also, have more juvenile diabetes and lymphomas (Mathur, 1993; Mayer, 1988).

Another immunological advantage of human milk is prophylaxis for allergies during breastfeeding and beyond (Goldman, 1993). The increase in childhood allergic diseases in the industrialized world has been related to the decrease in breastfeeding (Lawrence, 1994; Riordan \& Auerbach, 1999). Cow's milk is highly suspected as one cause of asthma, croup, and some skin diseases. Genetic heritage, also, influences the development of allergic illnesses. If parents have a history of allergies, breastfeeding decreases the likelihood of babies developing allergies (Lawrence, 1994).

Specific amino acids and lipids in human milk promote the neurological system and cognition of the baby (Lawrence, 1994; Riordan \& Auerbach, 1999). This advantage was documented during the 1990's. Intelligence test results showed that children who drank mother's milk scored as much as one-half of a standard deviation higher than other children, when confounding variables were taken into account. These influences were found in full-term babies and even more so in preterm babies (Horwood \& Fergusson, 1998; Lucas, Morley, Cole, Lister, \& Leeson-Paynne, 1992; Rogan \& Galden, 1993; Temporoury, Otero, Polanco, \& Arribas, 1994).

Breastfeeding has advantages for family development (Lawrence, 1994; Riordan \& Auerbach, 1999). Breastfeeding encourages bonding between mother and baby, but the advantages to families surpass mother-baby bonding. The process of breastfeeding helps family members recognize and meet each other's needs. "Successful breastfeeding is an infant-led process" (Lawrence, 1994, p.273). This is because the baby controls the supply of breast milk. It 
is the amount of sucking that stimulated the release of hormones that produce mother's milk. Mother and baby are most involved with breastfeeding, but to be successful, support from all family members is needed. By working together they accomplish the goal of increasing the health of the newest family member. The enthusiasm of fathers and other family members is promoted by recognizing their concerns and increasing their knowledge of breastfeeding (Jordan \& Wall, 1990). Breastfeeding is time and energy consuming, but childcare itself is time and energy consuming. Mother's milk substitutes require time and care in preparation, and they are expensive (Cunningham, 1995; Riordan, 1997).

There are few medical contraindications to breastfeeding. Lawrence (1994) included maternal breast cancer, hepatitis B, cytomegalovirus, HIV, occasionally mammoplasty if the milk production system is compromised, active tuberculosis in the mother, recreational drug use by the mother, and life-threatening disease of the mother. Lawrence believed there are no babyrelated contraindications to breastfeeding except galatosemia, a genetic metabolic disorder. She recommended that all other babies have their mother's milk, by breastfeeding or through pumping.

Successful actions.

Successful breastfeeding actions are behaviors that result in breastfeeding comfort and duration. Some successful actions are related to the anatomy and physiology of the breast (Lawrence, 1994; Riordan \& Auerbach, 1999). Each breast consists of 15 to 25 milk-producing glands. Each gland is a separate system, with lobes that produce milk and ducts that carry the milk to the milk sinus. Fifteen to 25 milk sinuses pass under the areola. The babies' mouth needs to grasp both the nipple and the areola for the sinuses to empty. Each gland system empties separately through the nipple. The glands are surrounded by fatty tissue. Connective tissue 
supports the milk-producing glands and fat, so the breasts have a conical shape. The amount of fatty tissue is directly related to the size of the breasts but not to the ability of the breast to produce milk. All breasts have approximately the same number of glands.

If babies breastfeed frequently after birth, milk production is promoted and most initial breast engorgement, with accompanying pain, is prevented (Moon \& Humenick, 1989). In addition, specific techniques of latching on and of releasing the babies' mouth reduce pain during initiation of breastfeeding (Riordan \& Auerbach, 1999). Babies need to breastfeed 8 to 12 times a day. The milk supply becomes well established if the baby breastfeeds at both breasts during the first few weeks. Women who gave their babies pacifiers breastfed less frequently and had milk supply problems (Howard, Howard, Lanphear, deBlieck, Eberly, \& Lawrence, 1999). Babies can maintain a milk supply even though they do not breastfeed for several hours each day. However, to maintain an adequate supply, babies need to breastfeed frequently during the rest of the day. In many cultures, mothers regularly separate from their babies to work or for other activities and maintain an adequate milk supply (Baunslag \& Micheals, 1995).

During growth spurts, babies demand more breastfeeding (Lawrence, 1994; Riordan \& Auerbach, 1999). Many women interpret this demand to mean they are not making enough milk. If the baby does some extra breastfeeding and if the mother rests some, then, more mothers' milk is produced (Lawrence, 1994; Riordan \& Auerbach, 1999). Fatigue has been reported as a problem for many women during the first weeks after initiating breastfeeding (Wambach, 1998).

In most cases, women do not need to change their diet to breastfeed (Lawrence, 1994; Riordan \& Auerbach, 1999). Even malnourished women in poor countries, who breastfed for a second year, had toddlers with satisfactory growth (Marquis, Habicht, Lanata, Black, \& Rasmussen, 1997). Pregnancy vitamins are continued. Complicated directions about diet can be a 
barrier, and such directions do not consider mothers' stores of nutrients. Breastfeeding requires only about 500 extra calories a day over women's pre-pregnancy diet. An apple, a peanut butter and jelly sandwich and a glass of milk suffice. Thirst takes care of the extra fluid needed. If babies react to a certain food that mothers eat, then that food can be avoided. Women have exercised, even heavily, and maintained satisfactory milk supplies (Fly, Uhlin, \& Wallace, 1998).

Most drugs pass minimally into the breast milk (American Academy of Pediatrics, Committee on Drugs, 1994). Careful selection of medication for breastfeeding women avoids harm to babies (Riordan \& Auerbach, 1999). Knowledge of pharmakinetics guides medication selection. Drug activity in fatty tissue is important since milk-producing glands are surrounded by fat. In addition, timing of drug administration is important. If a drug was taken immediately after breastfeeding, the drug level at the next feeding time was decreased (Dillion, 1997). Drug manufacturers may have been over-cautious about the safety of drugs during lactation because of fear of lawsuits (Lawrence, 1994). Recreational drugs definitely are harmful to babies (Lawrence, 1994).

The time for weaning varies by culture (Dettwyler, 1995; Greiner, 1996). The world average for complete cessation of breastfeeding has been 4.2 years (Lawrence, 1994). In this country, full breastfeeding has been recommended for 4 to 6 months. Then, other foods are introduced for swallowing practice with solid foods and for developing additional food tastes. A satisfactory method of weaning is to drop one daily feeding each week. This schedule allows adjustment for both mothers and babies (Riordan \& Auerbach, 1999). 
Cultural beliefs.

Cultural beliefs have challenged the practice of breastfeeding in the United States. Breastfeeding's cultural context was explained through the concept of nipplephobia. Nipplephobia is a concept that was conceived by Gaskins, a midwife. She named the phenomena of discomfort that a majority of people in the United States feel at the sight of a baby breastfeeding As a result of nipplephobia, breastfeeding women experience rudeness and irrational behavior from others, both in public and at home (Friedman, 1998).

Some young people, even in college, have not realized that the primary natural function of human breasts is to produce milk for human babies (Baumslag \& Micheals, 1995; Dettwyler, 1995). Instead, many people perceive women's breasts as primarily sex objects, "and not body parts elegantly designed for feeding children” (Dettwyler, 1995, p. 195). Furthermore, small breasts are often considered a disease to be treated by breast augmentation surgery (Dettwyler, 1995). Yet, small breasts feed a baby as well as large breasts do (Lawrence, 1994). In the past, breast augmentation surgery has destroyed the breast's milk production system (Riordan \& Auerbach, 1999).

Some mothers have interpreted feelings during breastfeeding as sexual (Lawrence, 1994). As a result, incest has been connected to breastfeeding by some in the United States. Most other cultures do not connect these two ideas (Baumslag \& Micheals, 1995; Dettwyler, 1995).

Often babies in this country sleep at some distance from their mothers (Baumslag \& Micheals, 1995). The average house in the United States is larger than houses in other countries. Often this greater distance between the sleeping mother and child requires greater effort on the mother's part to breastfeed during the night (Baumslag \& Micheals, 1995). 
Society has believed maternal employment to be a barrier to breastfeeding (Dettwyler, 1995). However, Lawrence (1994), in her review of breastfeeding literature, concluded that this belief was not substantiated. Milk could be pumped at work and given to the baby on another day. Several experts suggested that breastfeeding could ease the mother's return to work, because of the closeness that occurred with reuniting (Dettwyler, 1995; Lawrence, 1994; Riordan \& Auerbach, 1999).

Formula companies have advertised artificial milk as an equal to human milk that permits an easier lifestyle (Baumslag \& Micheals, 1995). Milk substitutes have less nutritional value and do not contain the other advantages of mother's milk (Cunningham, 1995; Lawrence, 1994, Riordan \& Auerbach, 1999). Milk substitutes are expensive. In addition, milk substitutes require time and care in mixing and are not safe if the water used for mixing is not healthful (Wong, 1999). In contrast, breast milk is always ready for the baby.

Because of breastfeeding's decline in the United States, knowledge about its practice has been lost to many women. Riordan and Auerbach (1999) stated that, for increased breastfeeding initiation and perseverance, both increased public awareness of breastfeeding's benefits and increased social acceptance were necessary. Breastfeeding knowledge needed to return to the public domain.

Nipplephobia, or cultural undermining of breastfeeding, has been prevalent in the health care profession, just as it has been in the general culture (Baumslag \& Micheals, 1995;

Dettwyler, 1995, Lawrence, 1994; Riordan \& Auerbach, 1999). Many health care professionals have expected breastfeeding failure and have given inaccurate and inappropriate advice about breastfeeding (Coreil, Bryant, Westover \& Baily, 1995; Izatt, 1997; Schanler, O’Connor \& Lawrence, 1999). In a large national study, only $37 \%$ of women were advised to consider 
breastfeeding by their health care providers (Sable \& Patton, 1998). As breastfeeding has become recognized as health promotion behavior, health professionals need effective breastfeeding promotion skills (Burglehaus, Smith, Sheps, \& Green, 1997) and confidence that a woman is capable of breastfeeding one baby or even twins (Hattori \& Hattori, 1999; Mozingo, 1996).

\section{$\underline{\text { Personal Efficacy Beliefs }}$}

Personal efficacy beliefs have predicted the initiation and perseverance of health promotion behavior (Bandura, 1992, 1995, 1997; Pender, 1996; Schwarzer, 1992). Pender (1996), a nurse, defined health promotion as approach behavior that increased overall well being. She defined health protection as behavior to avoid a specific illness, to discover it early, or to live as well as possible with illness. Pender stated that, although the motivation dynamics of health promotion and health protection may be different, the two were often complimentary processes. Effective behavior change models apply to both health promotion and health protection.

In 1991, a conference sponsored by the U. S. National Institutes of Health listed personal efficacy beliefs as one of eight theory-based health promotion variables (Fishbein, Bandura \& Trandis). Other variables named were (1) intention to perform; (2) minimal environmental constraints; (3) ability to perform or develop skills; (4) perception that benefits outweigh costs; (5) encouragement from social norms; (6) perception that behavior fit with self-standards; and (7) positive emotional reaction to behavior.

Pender organized these variables into her revised Health Promotion Model (1996) that described the likelihood of behavior occurring. In her model, individual characteristics and experiences combined with thoughts and feelings about behavior. Commitment to change and 
competing demands and/or preferences mediated all of these. Other people and situational factors influenced commitment to change. Her model also included three behavior specific cognitions. These behavior specific cognitions were personal efficacy beliefs, perceived advantages, and perceived barriers. Perceived advantages and perceived barriers were in the mind of the individual. Behavior specific feelings also occurred.

Personal efficacy beliefs are judgements of one's likelihood of success in completing specific behavior under different circumstances (Bandura, 1992, 1995, 1997). Schwarzer (1992), a health promotion researcher from Germany, described personal efficacy beliefs as:

People anticipate either optimistic or pessimistic scenarios in line with their level of self-efficacy....Actions are preshaped in thought....People with high selfefficacy choose to perform more challenging tasks.... Once an action has been taken, high self-efficacious persons invest more effort and persist longer than those low in self-efficacy....Self-efficacy beliefs are specific to different domains of functioning....Self-efficacy is based on experience and is not "the same as positive illusions or unrealistic optimism. (p. ix)

Personal efficacy beliefs are influenced by four factors (Bandura, 1992, 1995, 1997). The most significant influence is actual performance of behavior, or mastery learning. With breastfeeding, actual practice usually occurs after childbirth. Because of breastfeeding's hormonal control, once weaning occurs, substantial effort is required to reestablish breastfeeding. The second influence on personal efficacy beliefs is role modeling of behavior by others, or vicarious learning. Role modeling occurs when a woman watches breastfeeding or reads or hears about it, if the mother breastfeeding is a model. Gaskins' cure for nipplephobia, "watching great numbers of women breastfeed their children in public places," is role modeling and habituation 
that increases emotional comfort (Friedman, 1998). The third influence is verbal persuasion from another person about one's capability to perform behavior. This is symbolic learning. Verbal persuasion is communication that encourages a person's perceived capacity to accomplish behavior. It does not give information. Statements that promote personal efficacy beliefs are those slightly above the level of the perceived ability of the person being persuaded (Pender, 1996). If the statements, designed to promote personal efficacy beliefs, are too high they do not seem realistic. If the statements are too low, they are not challenging and do not increase personal efficacy beliefs (Pender, 1996). The final influence on personal efficacy beliefs is feeling comfortable while performing the behavior (Bandura, 1992, 1995, 1997).

Two authors have described personal efficacy beliefs about breastfeeding theoretically. One was the present author (Cleveland, 1999), who did so in a report of a pilot study discussed later in this chapter. The other was Dennis (1999) from the University of Toronto. Using Bandura's theory, she described four antecedents of breastfeeding confidence. The confidence antecedents were performance accomplishments, vicarious experience, verbal persuasion, and physiological and affective states. She illustrated with a diagram that breastfeeding confidence led to consequences or individual responses. Consequences were personal choice of behavior, effort and persistence, thought patterns, and emotional reactions. Finally, consequences resulted in activity. The types of activity were behavior initiation, performance and maintenance. Dennis reported that no studies describing personal efficacy beliefs about breastfeeding were available. In addition, Dennis could not find any studies "that specifically investigated the development of women's confidence in their ability to breastfeed" (1999, p. 195).

Recent interventions to promote breastfeeding have demonstrated three of the four factors that influence personal efficacy beliefs. Mother's groups such as La Leche League demonstrated 
effective social modeling and actual practice of breastfeeding as did peer counselor programs used in the federal Women, Infants and Children (WIC) programs. Peer counseling programs increased the rate of initial breastfeeding but not the rate of breastfeeding at six months (Long, Funk-Archuleta, Geiger, Mozar \& Heins, 1995). Comfortable behavior specific feelings were promoted by accurate and timely advice. Healthcare professionals were encouraged to confront their cultural beliefs, to obtain accurate information, and to develop counseling skills, as much poor advice has been offered (Coreil et al., 1995; Dettwyler, 1995). No research about verbal persuasion to increase perceived self-efficacy about breastfeeding was located.

Smith (1995) published a "score sheet for evaluating breast feeding educational materials" (p. 307). She listed six positive emotional themes for materials. "Milk-making is easy," instead of "you might not have enough." " Breast feeding is pleasant," instead of "breastfeeding is unpleasant." "Breastfeeding protects baby and mom," instead of "breastfeeding doesn't matter." "Baby and mom belong together," instead of "baby is inconvenient to mom. "Breastfeeding is fun and easy," instead of "breastfeeding is a hassle." And, finally, "we want you to breastfeed," not "we profit if you stop" (p. 309-310). This intervention of specific evaluation of educational materials was intended to influence behavior specific feelings.

Theoretically, personal efficacy beliefs about health promotion behavior are central to the initiation and preservation of that behavior. This variable has been important in Pender's revised Health Promotion Model. Personal efficacy beliefs have been increasingly recommended to promote a variety of health behaviors. The present author and another health care researcher, in separate articles, recommended their use to promote breastfeeding in two internationally refereed journals. 


\section{Empirical Investigations}

Three measurable characteristics of self-efficacy are possible. The first is magnitude or level or best performance. The second is strength or certainty of being able to perform. The third characteristic is generality of situations in which one could perform successfully (Bandura, 1992, 1995, 1997). Most measurement of personal efficacy beliefs have been of its magnitude (Schwarzer, 1992). Sherer, Maddux, Mercandante, Pectice-Dunn, Jacobs, and Rogers published a research instrument development guide for personal efficacy beliefs, in 1982, that has been used by some researchers in health promotion.

Empirical studies have demonstrated that the magnitude of personal efficacy beliefs has predicted the initiation and perseverance of new behaviors (Bandura, 1992, 1995, 1997; Pender, 1996; Schwarzer, 1992). Inaccurate feedback to subjects about their personal efficacy beliefs changed their actions to the inaccurate level of perceived ability in both individuals and groups. This has been demonstrated for both initiation and perseverance of behavior (BouffardBouchard, 1990; Litt, 1988; Prussia \& Kinicki, 1996).

Pender's (1996) Health Promotion Model was tested empirically in fifteen studies designed to promote various health behaviors. The data were collected by survey. Sample sizes ranged from 119 to 3,025 subjects with an average of 579 subjects and a median of 511 subjects. Personal efficacy beliefs explained the largest part of explained variance. Perceived barriers had strong significance and perceived advantages had moderate significance. Behavior specific feelings influenced personal efficacy beliefs. Finally, perceived barriers and commitment to action were influenced by personal efficacy beliefs.

Personal efficacy beliefs have been measured by surveys in other areas of health promotion. Horan, Kim, Gendler, Froman and Patel (1998) developed and evaluated a 21-item 
osteoporosis self-efficacy scale. They measured both exercise and calcium intake behaviors including initiation, maintenance and persistence of the behaviors by visual analogue in 201 women. Drummond and Rickwood (1997) piloted an inventory of childbirth personal efficacy beliefs with 100 women subjects. Both inventories had high internal consistency. Repeat reliability was not tested with either inventory. The osteoporosis inventory was supported for convergent validity and discriminant validity. The childbirth inventory was supported with Bandura's theory for construct validity.

Garcia, Norton-Broda, and Frenn (1995) studied exercise personal efficacy beliefs of 286 subjects. Covington and Omelich (1992) studied smoking personal efficacy beliefs of 6,494 subjects. Pender, Walker, and Sechrist (1990) studied personal efficacy beliefs about lifestyle changes of 576 cardiovascular disease sufferers. Holman and Long (1992) published four personal efficacy belief studies of arthritis self-management with 500, 97, 224, and 177 subjects. In these studies, personal efficacy beliefs were collected by survey. Then, the subjects took part in health promotion programs. After the programs, subjects' original personal efficacy beliefs were correlated with their life style changes. The original data were highly predictive of a subject's success in life style change.

In her recent article about the theoretical underpinning of breastfeeding confidence, Dennis (1999) reported the development of a 33 item self-report instrument to measure breastfeeding confidence of new mothers. This instrument was based on Bandura's theory and piloted on 130 new breastfeeding mothers. It used a 5-point Likert scale and predicted $(\underline{F}=9.89$, $\mathrm{p}<.001)$ which mothers would still be breastfeeding at 6 weeks after childbirth. The initial Cronbach's alpha was .96. Dennis reported evidence of two subscales, one about specific techniques about breastfeeding for new mothers and one about intrapersonal issues. Dennis 
based her work on Bandura’s 1977 and 1986 writings.

Recently, Cleveland (1999) developed the Personal Efficacy Beliefs about Breastfeeding Inventory (PEBBI) using developmental worldviews, breastfeeding, and personal efficacy beliefs knowledge. Personal efficacy beliefs guidelines directed that experts analyze conceptually the activity and then "refine their knowledge with interviews, open-ended surveys and structured questionnaires to identify the levels of challenge and impediment to successful performance of the required activities" (Bandura, 1997, p.43). "Ingenuity, exertion, accuracy, productivity, threat and self-regulation are challenges to personal efficacy belief” (Bandura, 1997, p.43).

Capabilities during the "development of mastery may differ from those required for on going self-regulation of behavior" (Bandura, 1997, p.45). If a behavior was new, then learning activities and motivation to learn needed to be part of personal efficacy beliefs (Bandura, 1997).

According to Bandura (1997), some personal efficacy beliefs were more important than other personal efficacy beliefs. Importance increased, as beliefs were more basic to the self. He directed that the list of items to assess efficacy be as comprehensive as possible because if the list was too limited, the tool would not reflect personal efficacy. Each item needed to be specific to the domain and not global because global measures have not been predictive of behavior.

Restricting items to those that correlate highly with one another results in a self-efficacy scale that measures redundantly only a segment of perceived efficacy and perhaps a narrow segment at that. (Bandura, 1997, p. 45)

Items may be ordered, mixed, or some combination of these, depending on the behavior. If certain activities were key to practice of the behavior, they needed to be first or in order of importance (Bandura, 1997).

The PEBBI reflected Bandura's (1997) recommendation that a visual analogue scale 
from 0 to 100 be used because he believed a scale of 0 to 10 was too limiting. To elicit selfefficacy, Bandura advised use of can do instead of will do. $\underline{\text { Can }}$ denoted capability, while will denoted intention. Capability predicted behavior significantly while intention did not. Bandura directed the use of "cannot do" with 0\%, "moderately certain can do" with $50 \%$ and "certain can do" with $100 \%$ on the scale. The PEBBI item visual analogue scale was exactly 100 millimeters long so that current confidence ratings were measured in percents.

The mean item score denoted strength of personal efficacy beliefs (Bandura, 1997). Lower mean scores denoted weak personal efficacy beliefs that were overcome easily. Higher mean scores denoted the likelihood of perseverance with the new behavior. Sometimes, a dividing line of mean score has been set to divide capable from incapable result. Factor analysis was used to identify the multifaceted structure of efficacy beliefs. Bandura wrote that item content needed to represent beliefs about the person's abilities to produce specified levels of performance and not other characteristics. Items needed to be sensitive to the difficulty levels of tasks and not indefinite. Accuracy of results depended upon the participant's feeling free from possible reactions of others concerning the participant's personal judgements.

The adequacy of self-efficacy measures can be evaluated independently, however, by evidence that they are measuring what they are purporting to measure and by their level specificity and the range of task demands they include. (Bandura, 1997, p. 45)

To Bandura (1997), construct validation was the most important evidence of validity. The importance of perceived efficacy beliefs was based on social-cognitive theory that identified the different ways they affected human functioning.

Self-efficacy measures gain validity from their demonstrated success in predicting 
the effects specified by the social cognitive theory in which the efficacy factor is imbedded. The theory predicts a variety of effects on thought, affect action, and motivation. Hence, there is no single validity coefficient. The vast body of research presented in this volume speaks to the validity of the construct. (p. 46)

The PEBBI (Cleveland, 1999) requested demographic information from each woman participant and contained 25 personal efficacy belief items. Example items were:

"I can breastfeed my baby at the mall."

$\begin{array}{ccc}\mid & & \\ 0 \% & 50 \% & 100 \% \\ \text { Certain cannot do } & \text { Moderately certain can do } & \text { Certain can do }\end{array}$

"I can have an attractive body while I breastfeed."

$\begin{array}{ccc}\mid & & \\ 0 \% & 50 \% & 100 \% \\ \text { Certain cannot do } & \text { Moderately certain can do } & \text { Certain can do }\end{array}$

Each woman answering made a mark at the place along the line that indicated her current level of confidence about doing the behavior as if she had a newborn baby. Since the line was 100 millimeters long, the placement of her mark was measured and the percentage of confidence determined.

The PEBBI was distributed to 56 women chosen by convenience in a small city with a university. The major question of the pilot was whether or not the PEBBI revealed differences between women about breastfeeding practice. Forty-two women, aged 18 to 81 years, returned the inventory. Their mean age was 39.7 years and their median age was 36 years. The estimated reliability coefficient for the PEBBI was 0.9219 . Forty-one women provided information concerning their education, occupation, spouse, pregnancy history, number of children, and breastfeeding duration and satisfaction. One woman 
did not report demographic information. Tables 1 through 3, on pages 37-39, summarize this information.

To answer the major question, the women were divided into groups by age, breastfeeding satisfaction, and motherhood experience. The distributions of their means were compared using independent-samples $t$ test (SPSS, 1998). Mothers with no breastfeeding experience or who reported low satisfaction and shorter duration

Table 1

Education and Occupation

\begin{tabular}{|c|c|c|c|}
\hline \multicolumn{2}{|c|}{ Education } & \multicolumn{2}{|c|}{ Occupation } \\
\hline Level & Number of women & Type & Number of women \\
\hline High School & 1 & Clerical Skills & 11 \\
\hline Vocational School & 4 & College Students & 7 \\
\hline Some College & 16 & $\begin{array}{c}\text { Professional or } \\
\text { Business }\end{array}$ & 14 \\
\hline Completed College & 13 & $\begin{array}{l}\text { At Home With } \\
\text { Children }\end{array}$ & 3 \\
\hline Graduate School & 7 & Retired & 6 \\
\hline
\end{tabular}


Table 2

$\underline{\text { Pregnancies and Children }}$

\begin{tabular}{lc}
\hline \multicolumn{1}{c}{ Pregnancies and children } & Number of women \\
\hline Never been pregnant & 15 \\
Had pregnancies & 26 \\
No children/woman older than 27 years & 10 \\
No children/woman younger than 27years & 7 \\
Children & $24(1-6$ children each $)$ \\
Currently pregnant & 2 \\
\hline
\end{tabular}


Table 3

Mothers' Breastfeeding Experience and Satisfaction

Mothers' breastfeeding experience and satisfaction Number of mothers

No breastfeeding experience

4

Low reported satisfaction

No breast milk after 1.5 months

6

High reported satisfaction

Breast milk ends between 1.5 and 12 months

14 
demonstrated significant differences in scores when compared to mothers with high reported satisfaction and longer duration. These values are reported in Table 4, on page 41 .

The scores of childless women under 27 years of age were compared to the scores of the experienced and satisfied breastfeeding mothers. All but one of the younger childless women reported being university students. The significantly different scores of the groups of women are summarized in Table 5, on page 42 .

Many of the women wrote comments and suggestions. Some women omitted items. Table 6 beginning on page 43, summarizes the comments, item omissions, and suggestions. The women participants were a convenience and not a random sample. Most of the women were part of a university community and known to colleagues of the author. The women varied in age and in breastfeeding experience. One woman marked high school as her highest educational level. The others reported more education.

Significantly different personal efficacy beliefs between satisfied breastfeeding mothers and the other groups were the effect of relationships on breastfeeding, the feelings a woman has about her body while breastfeeding, and some technical aspects of breastfeeding. Satisfied breastfeeders were more confident about breastfeeding with immediate family and extended family present, or at the mall. They were more confident in their belief about having an attractive body while breastfeeding. Satisfied breastfeeders were more confident about breastfeeding at birth and through a baby growth spurt. Mothers with no breastfeeding experience or low satisfaction were 
Table 4

Significant Differences in Scores of Mothers Grouped By Breastfeeding

Satisfaction

\begin{tabular}{|c|c|c|c|}
\hline \multirow{3}{*}{ Inventory items with $\mathrm{p}<.05$} & \multirow{2}{*}{\multicolumn{2}{|c|}{$\begin{array}{c}\text { Means of mothers grouped by } \\
\text { breastfeeding satisfaction }\end{array}$}} & \multirow{3}{*}{$\begin{array}{c}\text { Independent-samples } \mathrm{t} \\
\text { test } \\
(\mathrm{t}>1.753, \mathrm{df}=15)\end{array}$} \\
\hline & & & \\
\hline & None/Low & High & \\
\hline Overall Inventory Score & 66.5 & 88.4 & 2.993 \\
\hline "Breastfeed at the mall" & 52.1 & 92.1 & 3.335 \\
\hline \multicolumn{4}{|l|}{ "Have an attractive body while I } \\
\hline breastfeed" & 72.6 & 96.1 & 2.694 \\
\hline \multicolumn{4}{|l|}{ “Expect support of my baby’s } \\
\hline father" & 61.1 & 90.9 & 2.661 \\
\hline \multicolumn{4}{|l|}{ "Breastfeed through a growth } \\
\hline spurt" & 59.6 & 89.0 & 2.392 \\
\hline \multicolumn{4}{|l|}{ "Provide $85 \%$ or more of baby's } \\
\hline diet" & 53.0 & 83.9 & 2.314 \\
\hline \multicolumn{4}{|l|}{ "Breastfeed my baby right after } \\
\hline birth" & 82.6 & 97.7 & 2.294 \\
\hline \multicolumn{4}{|l|}{ "Breastfeed with my extended } \\
\hline family present" & 68.8 & 91.0 & .256 \\
\hline \multicolumn{4}{|l|}{ "Breastfeed with my immediate } \\
\hline family present" & 82.3 & 95.7 & 2.182 \\
\hline
\end{tabular}


Table 5

Significant Differences in Scores Of Younger Childless Women and Satisfied Breastfeeders

\begin{tabular}{|c|c|c|c|}
\hline \multirow[t]{3}{*}{ Inventory items with $\mathrm{p}<.05$} & \multicolumn{2}{|c|}{ Means of groups of women } & \multirow{3}{*}{$\begin{array}{c}\text { Independent-samples } t \\
\text { test } \\
(t>1.761, \mathrm{df}=14)\end{array}$} \\
\hline & Younger/ & Satisfied & \\
\hline & childless & breastfeeders & \\
\hline Overall Inventory Score & 73.7 & 88.3 & 2.338 \\
\hline \multicolumn{4}{|l|}{ "Breastfeed with my immediate } \\
\hline family present" & 63.4 & 95.7 & 3.211 \\
\hline :Breastfeed right after birth" & 84.7 & 97.7 & 2.936 \\
\hline "Breastfeed at the mall" & 55.3 & 92.1 & 2.826 \\
\hline \multicolumn{4}{|l|}{ "Breastfeed with my extended } \\
\hline family present" & 58.7 & 91.0 & 2.678 \\
\hline \multicolumn{4}{|l|}{ "Breastfeed through a growth } \\
\hline spurt" & 63.4 & 89.0 & 2.667 \\
\hline \multicolumn{4}{|l|}{ "Have an attractive body while I } \\
\hline breastfeed" & 69.1 & 96.2 & 2.552 \\
\hline \multicolumn{4}{|l|}{ "Learn to get my baby on and off } \\
\hline the breast" & 82.2 & 95.9 & 2.437 \\
\hline \multicolumn{4}{|l|}{ "Make milk that is safe for my } \\
\hline baby" & 81.4 & 95.7 & 2.369 \\
\hline \multicolumn{4}{|l|}{ "Make enough milk no matter the } \\
\hline size of my breasts" & 60.1 & 85.5 & 2.125 \\
\hline
\end{tabular}


Table 6

Written Comments, Item Omissions, Suggestions of Participants

\begin{tabular}{|c|c|}
\hline Item & $\begin{array}{l}\text { Written Comments, Omissions and Suggestions of } \\
\text { Participants }\end{array}$ \\
\hline "Breastfeed my baby at the mall" & $\begin{array}{l}\text { "Have had to." ( } 32 \text { years old, } 2 \text { children, high } \\
\text { satisfaction and currently weaning her } 9 \text { month old.) } \\
\text { "Been there, done that." ( } 32 \text { years old, } 2 \text { children, } \\
\text { high satisfaction) }\end{array}$ \\
\hline $\begin{array}{l}\text { "Pump milk at work and give it to } \\
\text { my baby." }\end{array}$ & $\begin{array}{l}\text { Item omitted. ( } 43 \text { years old, } 6 \text { children, high } \\
\text { satisfaction, } 12 \text { months breastfeeding duration, } \\
\text { wife/mother) }\end{array}$ \\
\hline $\begin{array}{l}\text { "Breastfeed my baby through a } \\
\text { growth spurt." }\end{array}$ & $\begin{array}{l}\text { Items omitted. ( } 71 \text { years old, } 2 \text { children, low } \\
\text { satisfaction, wrote “n/a" for spouse's occupation) }\end{array}$ \\
\hline $\begin{array}{l}\text { "Expect support of father of my } \\
\text { baby for breastfeeding." }\end{array}$ & \\
\hline $\begin{array}{l}\text { "Learn to get my baby on and off } \\
\text { the breast." }\end{array}$ & "I don't understand." (25 years old, no children) \\
\hline "Get help caring for my baby & "??”' (29 years old, no children, currently pregnant \\
\hline while breastfeeding." & $\begin{array}{l}\text { and marked item at } 45 \% \text { ) } \\
\text { "This can be tough." ( } 32 \text { years old , } 2 \text { children, } \\
\text { breastfeed for } 9 \text { months with high satisfaction) }\end{array}$ \\
\hline
\end{tabular}


“Provide $85 \%$ of my baby's diet through breastfeeding"

“Provide 50\% of my baby's diet through breastfeeding."

“Provide $85 \%$ of my baby's diet through breastfeeding."

"Breastfeed my baby right after birth."

"Breastfeed my baby for one year."

Suggestions for additional items.
Item omitted. "I have tried. Personally, I couldn't do it but I wish that I could have done it" (46 years old, 4 children, low satisfaction) Item omitted. (34 year old, 2 children, no breastfeeding experience)

'I'm not sure what you mean, exactly. If the baby is a newborn and not on solids, would the alternative be formula or something else? $100 \%$ would indicate a purely breastfed baby?" (32 years old, 2 children, high satisfaction and currently weaning her 9 month old.)

"Until a certain age." (24 years old, 2 children, no breastfeeding experience)

"As soon as the milk comes in." "Was not able to breastfeed as long as desired." (67 years old, 4 children)

"I think this is too long." (24 years old, 2 children, no breastfeeding experience)

"Night-time breastfeeding."

"Getting pregnant while breastfeeding."

"Difficulty of returning to work."

"Alcohol and drugs while breastfeeding." 


"Animosity of others toward breastfeeding."
"Problems of milk supply." (Suggested twice)
"Baby characteristics or temperament."
"Receiving encouragement of mothers or
grandmothers for breastfeeding."
"Discomfort while learning to breastfeed."
"Breastfeeding is far above bottle. Highly
recommended if possible."( 2 children, no age
reported, high satisfaction)
"Such a quick and easy survey." (32 years old, 2
children, high satisfaction and currently weaning her
9 month old.)


less confident in their belief of expecting father support. Younger childless women were less confident about having adequate breast size. Younger childless women were less confident about learning to get baby on and off the breast and making safe milk. Because this sample of women was nonrandom and small, these personal efficacy belief results are preliminary.

The PEBBI was revised after the pilot. Several items were revised for clarity. The two items on percentage of mother's milk in babies' diet ("I can provide 50\% of my baby's diet by breastfeeding," and I can provide $85 \%$ of my baby's diet by breastfeeding) were combined into one item. This item reads, "I can provide all my baby's food for several months by breastfeeding." Eating and drinking as women pleased was changed to include only eating because having alcohol is called having a drink. Eating and drinking as women pleased were separated. An additional item about using needed drugs was added. From the suggestions of the participants, two items were added, returning to work and nighttime breastfeeding. The instrument was renamed the Inventory of Breastfeeding Personal Efficacy Beliefs, here after called the inventory.

Implications of the pilot study included enhancement of breastfeeding promotion through application of personal efficacy beliefs and developmental worldviews. Younger women could be encouraged to express their needs and preferences about breastfeeding. As younger women talk, the health professional could provide accurate information about the mechanics of breastfeeding. All women could be encouraged to learn vicariously and symbolically so they were more confident about the attractiveness of breastfeeding and about breastfeeding right after birth, at the mall, and with family and friends present. Women closely connected to a tradition have been likely to follow its mandates. Community health promotion methods could be used to influence community traditions. 
Individual women could to be encouraged toward self-regulated behavior. As women have regulated their behavior, they increasingly influence their family and friends.

\section{Statement of the Problem}

Breastfeeding significantly increases the health of babies. But, breastfeeding rates are low in the United States because of cultural undermining. The World Health Organization, the United States Government and the American Academy of Pediatrics recommend breastfeeding for healthier babies.

Breastfeeding is health promotion behavior. Personal efficacy beliefs (Bandura, 1992, 1995, 1997; Pender, 1996) are important in changing health behavior because personal efficacy beliefs predict health behavior initiation and perseverance. Personal efficacy beliefs (Bandura, 1992, 1995, 1997; Pender, 1996) are judgements a person makes about personal ability to accomplish behavior in a variety of situations. Four influences on personal efficacy beliefs are actual practice of behavior, role modeling of behavior, verbal persuasion about personal efficacy to accomplish behavior and emotional comfort while performing behavior (Bandura, 1992, 1995, 1997; Pender, 1996). Knowledge about women's personal efficacy beliefs can aid the design of interventions that increase breastfeeding.

College women are in the process of developmental worldview expansion (Kegan, 1982, 1994, 1998). Because of current developmental worldview knowledge, women interested in university education might initiate breastfeeding with lesser amounts of intervention. Health professionals need interventions that increase the initiation and perseverance of breastfeeding.

The author, using developmental worldviews, breastfeeding and personal efficacy belief knowledge, previously developed the PEBBI. In a pilot study, the PEBBI was used to describe 
women's personal efficacy beliefs about breastfeeding. The inventory used in this study is a slightly modified version of the previous PEBBI.

\section{Research Questions}

The research questions of this dissertation are designed to gather information about the development of women's breastfeeding personal efficacy beliefs. University women can be expected to vary in age, in developmental worldview, and motherhood experience. The younger childless women in the pilot study had significantly different breastfeeding personal efficacy beliefs from the mothers with breastfeeding experience.

The investigation is designed to examine the following three questions. What are the breastfeeding personal efficacy beliefs of West Virginia University women students as measured by the Inventory of Breastfeeding Personal Efficacy Beliefs? How reliable and valid is the Inventory? Do women's breastfeeding personal efficacy beliefs correlate to academic progress as demonstrated by academic rank as measured by number of achieved college credits? 


\section{Chapter 3}

\section{METHOD}

This chapter contains the research methods (Burns \& Grove, 1993; McMillian \& Schumacher, 1997) used to investigate the three research questions. First, the instrument is presented; then, the population is discussed; the procedure is described next; and analysis plan concludes the chapter.

\section{Instrument}

The instrument for this dissertation was the Inventory of Breastfeeding Personal Efficacy Beliefs found in the Appendix on page 90. This inventory has 27 visual analog items. Each item contains a statement of a breastfeeding personal efficacy belief followed by a 100-millimeter line. The anchors of the line are "cannot do" at $0 \%$, "moderately certain can" at the middle of the line and "certain can do" at 100\%. The phrase, "Please mark your current level of confidence as if you had a newborn baby," is presented at the top of the 3 pages of breastfeeding personal belief items. Each item begins with "I can," and describes a situation related to breastfeeding babies. An inventory score can be calculated by finding the mean score of the 27 items. A demographics page follows the visual analog items. It gathers information about comments and suggestions about the personal efficacy belief items, age, earned college credits, college major, occupation of spouse if appropriate, and history of pregnancy, children, and breastfeeding. The inventory was a revised version of PEBBI utilized in a pilot study previously conducted by this author and described in the empirical investigations section of the literature review chapter. The readability level of the inventory is 7 th grade (Frye, 1977). 


\section{Population}

The population for this study was women students attending West Virginia University during the spring semester of 2000. According to the student data services office, $17.1 \%$ of university students were freshmen, $16.9 \%$ were sophomores, $13.6 \%$ were juniors, $19.9 \%$ were seniors, $27.6 \%$ were graduate students, and $4.9 \%$ were professional students.

\section{Procedure}

Exemption status was obtained from the College of Human Resources and Education Institutional Review Committee. Then, a list of 700 randomly selected enrolled women students from The Student Data Services Office was obtained. A return goal of 400 responses was set so that the sampling error would be as low as possible considering the resources of the author (Fink, 1995:Mangione, 1995).

Each woman student selected for the sample was mailed a confidential inventory during the spring semester of 2000. A mail survey was appropriate for the collection of breastfeeding personal efficacy data for several reasons, which Mangione (1995) delineated. The items were close-ended and visual in mode. The inventory was modest in length. In addition, personal efficacy beliefs are more accurately revealed without social judgement (Bandura, 1997), and the author had limited time, money, and human resources for conducting the study.

A participant number was placed in rectangular boxes on the inventory to keep track of the returns. A letter explaining the study and the reasons that responding was important accompanied the mailing. In addition, a page of instructions and a return envelope with an attractive commemorative stamp was mailed with the inventory. The pages were copied front and back, so that the mailing was 3 pages. The first page was blue and the next two were white. 
A small money incentive of $\$ 2$ was sent with the inventory. The mailing was packed for an initial attractive presentation. Blue and white paper framed the green money and the commemorative stamp. Mangione (1995) reported from his review of the mail survey techniques that small amounts of prepaid money increase return rates of surveys more that larger amounts of money paid after the return of the survey. He speculated that money prepaid implies trust and so increases return rates. In addition, confidentiality is easier to maintain if the participant is prepaid. A follow-up postcard with a bright design was sent to the non-responders two weeks after the initial mailing (Mangione, 1995).

\section{Analysis}

Three research questions directed the data analysis plan. University women's confidence about breastfeeding was addressed in the first question. The reliability and validity of a new research instrument that measured breastfeeding personal efficacy beliefs was considered in the second question. The final question addressed women's breastfeeding confidence related to academic level

Frequency statistics described the population sample. Descriptive statistics analyzed the item scores and normality of the inventory scores. The data collection procedures analyzed for accuracy, and the internal consistency of the research instrument were calculated for reliability. Factor analysis and comparing means of sample sub-groups analyzed construct validity. Finally, the independent variables were examined by regression analysis exploratory prediction of inventory score. 


\section{Chapter 4 \\ RESULTS}

The research methods results are contained in this chapter. The results of frequency and descriptive analysis are presented first. Then, interpretive reliability and internal consistency are described. Finally, construct validity is analyzed through factor analysis, comparison of group means and exploratory regression analysis.

\section{Frequency and Descriptive Analysis}

Inventories from 494 or $70.6 \%$ of the 700 randomly selected women students were returned in the mail to the author's private residence. Five women had not completed their inventories; a male student returned another. The inventories from these six students were put aside, and 488 or $69.7 \%$ of the inventories were analyzed.

Demographic information revealed that the participants ranged in age from 17 years to 59 years with a mean age of 25.67 , a median age of 22 and a mode age of 20

$(\mathrm{n}=488)$. In Table 7, on page 53, are listed the participants' academic level. When compared with the total woman university population, freshmen participant frequency was $15 \%$ lower, sophomore frequency was $1 \%$ lower, junior frequency was $13 \%$ lower, senior frequency was 12 $\%$ lower, professional student frequency was $20 \%$ lower, and graduate student frequency was 9 $\%$ higher. Grade point averages (GPAs) ranged from 1.0 to $4.0(\mathrm{n}=452)$. The mean GPA was 3.33, the median was 3.41 , and, the mode was 4.00 (60 participants). Thirty-six participants ( 7.4 \%) did not report their GPA. Most participants had selected a major of study. The selected majors reported by the participants covered the range offered by the university. 
Table 7

Summary of Participants' Academic Experience $(n=488)$

\begin{tabular}{lcccc}
\hline Variable & Frequency Returned & Percent & Percent Returned & Percent \\
& & Mailed & Reported \\
\hline Level & 67 & 17.1 & 13.7 & 14.5 \\
Freshman & 79 & 16.9 & 16.2 & 17.1 \\
Sophomore & 55 & 13.6 & 11.3 & 11.9 \\
Junior & 104 & 19.9 & 21.3 & 22.5 \\
Senior & 18 & 4.9 & 3.7 & 3.9 \\
Professional & 140 & 27.6 & 28.7 & 30.2 \\
Graduate & & & & \\
\hline
\end{tabular}


Breastfeeding and pregnancy experiences of the participants were summarized in Table 8 , on page 55. Of the participants, 367 (75.2\%) had no children; 45 (9.2\%) had one child; 55 (11.3 $\%)$ had two children; 14 (2.9\%) had three children; and $5(1 \%)$ had four children. Two (.4\%) participants did not report number of children. Breastfeeding satisfaction of sisters or close friends was reported as none by $220(45.1 \%)$ participants, low by 24 (4.9\%) participants; medium by 71 (14.5\%) participants; and high by 169 (34.6\%) participants. This item was not reported by $4(.8 \%)$ participants. Breastfeeding length ranged from two weeks to 48 months. One participant did not report a breastfeeding length. The mean length of breastfeeding was 8.7 months, the median was 6 months and the mode was one month. During the early months, breastfeeding was the baby's full diet for 50 (10.2 \%) participants, a high part of baby's diet for 6 (1.2\%), a medium part of baby's diet for $3(.6 \%)$, a low part of baby's diet for $2(.2 \%)$, and a token part of baby's diet for $8(1.6 \%)$. Three breastfeeding participants (.6\%) did not report diet amount. High breastfeeding satisfaction was reported by 47 (9.6\%) participants, medium satisfaction was reported by $9(1.8 \%)$, and low satisfaction was reported by $13(2.7 \%)$. Four (.8\%) did not report their breastfeeding satisfaction.

The inventory had 27-visual analogue items measuring breastfeeding personal efficacy beliefs. Participant's used the total scale available, from $0 \%$ to $100 \%$. Table 9 , beginning on page 56 , listed item means. The item left blank by most the participants $(6 \%)$ was confidence in ability to breastfeed through a growth spurt. Several participants added handwritten comments about their lack of familiarity with this idea.

Distributions of most items were skewed negatively. Five items with the most skew were participant's confidence in ability to obtain information about breastfeeding 
Table 8

Summary of Participants' Pregnancy and Breastfeeding Experiences $(\mathrm{n}=488)$

\begin{tabular}{|c|c|c|}
\hline Variable & Frequency & Percent \\
\hline \multicolumn{3}{|l|}{ Breastfed as baby } \\
\hline yes & 219 & 44.9 \\
\hline no & 227 & 46.5 \\
\hline don't know & 42 & 8.6 \\
\hline \multicolumn{3}{|l|}{ Ever pregnant } \\
\hline yes & 121 & 24.8 \\
\hline no & 364 & 74.6 \\
\hline missing & 3 & 6 \\
\hline \multicolumn{3}{|l|}{ Pregnant now } \\
\hline yes & 8 & 1.6 \\
\hline no & 476 & 97.5 \\
\hline missing & 4 & .8 \\
\hline \multicolumn{3}{|c|}{ Sister/close friend breastfed } \\
\hline yes & 272 & 55.7 \\
\hline no & 213 & 43.6 \\
\hline missing & 2 & 6 \\
\hline \multicolumn{3}{|l|}{ Participant breastfed } \\
\hline yes & 72 & 14.8 \\
\hline no & 413 & 84.6 \\
\hline missing & 3 & .6 \\
\hline
\end{tabular}


Table 9

Means of Participants' Breastfeeding Personal Efficacy Beliefs

\begin{tabular}{|c|c|c|c|}
\hline Confidence about ability to: & $\underline{\mathrm{M}}$ & $\underline{\mathrm{SE}}$ & $\underline{\mathrm{n}}$ \\
\hline improve my baby's health & 83.4 & 20.3 & 487 \\
\hline get information about breastfeeding & 92.7 & 15.8 & 487 \\
\hline breastfeed at the mall & 54.9 & 36.0 . & 485 \\
\hline breastfeed with extended family present & 63.5 & 35.0 & 487 \\
\hline breastfeed with immediate family present & 79.0 & 29.5 & 488 \\
\hline pump@work and save my milk for baby & 58.9 & 35.6 & 486 \\
\hline breastfeed through a growth spurt & 62.6 & 30.6 & 458 \\
\hline make enough milk no matter breast size & 75.8 & 26.2 & 485 \\
\hline have attractive body while breastfeeding & 78.7 & 24.2 & 486 \\
\hline learn to get baby on and off the breast & 83.5 & 21.2 & 486 \\
\hline make milk that is safe for my baby & 87.2 & 17.7 & 488 \\
\hline eat mostly as I please & 56.1 & 30.7 & 486 \\
\hline get help with the baby while breastfeeding & 80.0 & 23.2 & 483 \\
\hline expect support from my baby's father & 84.5 & 23.4 & 479 \\
\hline improve my baby's intelligence & 58.3 & 33.0 & 475 \\
\hline have a pleasant time while breastfeeding & 75.8 & 26.8 & 485 \\
\hline breastfeed during the nighttime & 87.6 & 17.9 & 488 \\
\hline save money by breastfeeding & 87.4 & 19.2 & 486 \\
\hline take most drugs I need while breastfeeding & 28.5 & 27.1 & 485 \\
\hline bond easily with my baby & 90.0 & 16.4 & 486 \\
\hline
\end{tabular}




\begin{tabular}{|c|c|c|c|}
\hline ease my return to work by breastfeeding & 50.3 & 29.0 & 475 \\
\hline do most activities that I want & 67.5 & 29.5 & 482 \\
\hline provide all my baby's food during early months & 66.4 & 31.1 & 481 \\
\hline breastfed right after birth & 81.3 & 23.8 & 483 \\
\hline breastfeed for three months & 83.4 & 22.4 & 485 \\
\hline breastfeed for six months & 75.9 & 27.4 & 482 \\
\hline breastfeed for one year & 56.7 & 36.4 & 480 \\
\hline
\end{tabular}


(-3.313), to bond with the baby (-2.559), to feed the baby during the nighttime (-2.042), to expect support from the father for breastfeeding (-2.012), and to save money (-1.928).

Most items were distributed in a platykurtic or flattened curve. Five items with the most platykurtic curve were confidence in ability to get information (12.435), to bond with the baby (7.794), to breastfeed during the nighttime (4.755), to save money (3.393), and to make safe milk (3.339).

Inventory scores of 488 women student responders were calculated. The mean of this distribution was $72.2 \%$ with a standard deviation of $14.6 \%$ and a standard error of $0.66 \%$. Inventory scores ranged from $15.48 \%$ to $100.00 \%$. The median of the distribution was $73.3 \%$. The variance statistic was 213 , the skewness statistic was -.441 , and the kurtosis statistic was .086 .

Interpretive Reliability

\section{Reliability}

Examination of interpretive reliability included the accuracy of data collection, measurement of visual analogue items, data entry, and statistical methods. Procedures for data collection were described in Chapter 3. These included obtaining names and addresses of randomly selected women students, initial mailing, and second mailing. In addition, visual analogue measurement was described in Chapter 3. Two people entered the data into the software program. Each entered about half the data and checked the other half for accuracy. Screening the data included consideration of missing data, grouping data, and exploring it for normalcy. Missing data were not replaced and data were not grouped. One independent variable, participant's decision about a major was dropped from analysis. Participants who reported deciding on a major were more than $90 \%$ of the total and participants who reported no major decision were less than $10 \%$. Many participants with lower academic rank reported GPAs that 
did not support admission to their chosen majors. Finally, computer software calculated the statistical measures and the calculations were repeated for accuracy.

$\underline{\text { Internal consistency }}$

Internal consistency included examining the homogeneity of the dependent variables. The Cronbach alpha coefficient of the 27 items was $.9132(n=422)$. The Cronbach alpha coefficient for the earlier version of the inventory, the PEBBI was $.9219(\mathrm{n}=42)$.

\section{Validity}

\section{$\underline{\text { Factor Analysis }}$}

Construct validity was examined through factor analysis of the 27-personal efficacy belief items. In preparation for factor analysis, correlation coefficients between items were calculated, and several groupings of correlation coefficients were evident. Therefore, participant responses were analyzed by principal component analysis and varimax rotation. Criteria used to select the number of factors and number of items within a factor were Eigenvalue greater than 1 and a loading factor of .30 (Burns \& Grove, 1993). All 27 items met the criteria and accounted for $55 \%$ of the explained variance. Names of the factors and items, together with factor loading and percentage of Eigenvalue were shown in Table 10, on page 60. Five factor means were calculated by summing the item ratings and dividing by the number of items in the respective factor. The five factor means were "When" (75.2\%), "How" (84.1\%), "Who" (64.1\%), "What" (62.9\%), and "Why" (64.1\%). The "When" factor had a Cronbach's alpha of .8207. 
Table 10

Factor Analysis of Breastfeeding Personal Efficacy Beliefs ( $n=487$ )

\begin{tabular}{|c|c|c|c|c|c|}
\hline Item Name & When? & How? & Who? & What? & Why? \\
\hline Six months & .867 & .135 & .171 & --- & .119 \\
\hline Three months & .821 & .261 & --- & --- & .124 \\
\hline One year & .691 & --- & .300 & .166 & --- \\
\hline Right after birth & .545 & .396 & .164 & .134 & .167 \\
\hline Provide all food & .473 & --- & .174 & .359 & .370 \\
\hline Save money & .399 & .328 & .108 & .214 & .309 \\
\hline Expect support from father & --- & .673 & .102 & --- & .249 \\
\hline Bond with baby & .256 & .573 & --- & .103 & .270 \\
\hline During the nighttime & .408 & .568 & --- & --- & .204 \\
\hline Learn on and off & .192 & .559 & .185 & .351 & --- \\
\hline Have a pleasant experience & .213 & .496 & .266 & --- & .444 \\
\hline Get help with baby & .337 & .470 & .147 & .342 & --- \\
\hline Get information & --- & .473 & .245 & .119 & -.283 \\
\hline Have an attractive body & .293 & .395 & .193 & .395 & --- \\
\hline Extended family present & .158 & .151 & .879 & --- & .122 \\
\hline Immediate family present & --- & .182 & .854 & --- & --- \\
\hline At the mall & .238 & .112 & .763 & .197 & --- \\
\hline Pump at work & .264 & .106 & .528 & .287 & .160 \\
\hline Eat as I please & --- & .125 & --- & .700 & --- \\
\hline Take most drugs I need & --- & --- & .201 & .639 & .234 \\
\hline
\end{tabular}




\begin{tabular}{lccccc}
\hline Make safe milk & .212 & .376 & --- & $\underline{.527}$ & --- \\
Breast size doesn't matter & .397 & .196 & --- & $\underline{.524}$ & .133 \\
Feed through growth spurt & .319 & .238 & .302 & $\underline{.489}$ & .239 \\
Do most activities & .269 & .199 & .172 & $\underline{.400}$ & .232 \\
Increase baby's intelligence & .134 & --- & --- & .166 & $\underline{.749}$ \\
Increase baby's health & .275 & .291 & .154 & --- & $\underline{.590}$ \\
Ease return to work & --- & --- & .142 & .334 & $\underline{.567}$ \\
$\quad$ Eigenvalues & 8.841 & 1.843 & 1.541 & 1.433 & 1.207 \\
\hline
\end{tabular}

Note. The item factor loading statistic that is underlined indicates the sub-scale to which each item was assigned. 
The "How" factor had a Cronbach's alpha of .7775. The "Who" factor had a Cronbach's alpha of .8251. The "What" factor had a Cronbach's alpha of .7245. Finally, the "why" factor had a Cronbach's alpha of .6192.

One Way Analysis of Variance

In preparation for one way analysis of variance, correlation coefficients of inventory scores and of breastfeeding, mother, and educational levels were calculated. Patterns of correlation coefficients were evident, so one way analysis of variance (ANOVA) was conducted. Childless participants had a mean score of $69.9(\underline{s d}=13.9)$, while mothers had a mean score of $80.6(\underline{s d}=13.5)$. Inventory scores of childless participants were significantly different at the .01 level from inventory scores of mothers. Table 11, on page 63, listed ANOVA results of mothers and non-mothers. Non-breastfeeders, both childless women and mothers, had a mean inventory score of $70.2(\underline{\mathrm{sd}}=13.7)$. Non-breastfeeders were significantly different at the .01 level from breastfeeding mothers whose mean inventory score was $84.1(\underline{s d}=14.0)$. Table 12 , on page 64 , listed ANOVA results for breastfeeders and non-breastfeeders. Participants of different academic levels were significantly different at the .01 level in inventory scores. The means of the academic levels were: 66.4 for freshmen $(\underline{s d}=12.8), 68.9$ for sophomores $(\underline{s d}=13.0), 71.8$ for juniors $(\underline{s d}$ $=15.7), 72.2$ for seniors $(\underline{s d}=15.7), 77.0$ for graduate students $(\underline{s d}=13.7)$, and 75.8 for professional students $(\underline{s d}=10.4)$. Table 13 , on page 65 , listed ANOVA results for the academic levels. The Scheffe post hoc test was significant at the .05 level for graduate students and two other levels. Graduate students had inventory means 10.66 higher than freshmen and 8.16 higher than sophomore students. 
Table 11

Analysis of Variance for Inventory Scores of Mothers and Non-Mothers

\begin{tabular}{ccccccc}
\hline Source & $\underline{\text { Df }}$ & $\underline{\text { SS }}$ & $\underline{\text { MS }}$ & $\underline{\text { F }}$ & $\underline{\text { F probability }}$ \\
\hline Between groups & 1 & & 10849.015 & 10849.015 & 56.716 & .0001 \\
Within groups & 486 & & 92.965 .283 & 191.287 & & \\
TOTAL & 487 & 103814.297 & & & \\
\hline
\end{tabular}


Table 12

Analysis of Variance for Inventory Scores of Breastfeeders and Non-breastfeeders (Mothers and Childless)

\begin{tabular}{cccccc}
\hline Source & $\underline{\mathrm{df}}$ & $\underline{\mathrm{SS}}$ & $\underline{\mathrm{MS}}$ & $\underline{\mathrm{F}}$ & $\underline{\text { F probability }}$ \\
\hline Between groups & 1 & 11957.521 & 11957.521 & 62.991 & .0001 \\
Within groups & 483 & 91688.033 & 189.830 & & \\
TOTAL & 484 & 103645.554 & & & \\
\hline
\end{tabular}


Table 13

Analysis of Variance for Inventory Scores of Participants Grouped by Academic Level

\begin{tabular}{cccccc}
\hline Source & $\underline{\mathrm{df}}$ & $\underline{\mathrm{SS}}$ & $\underline{\mathrm{MS}}$ & $\underline{\mathrm{F}}$ & $\underline{\text { F probability }}$ \\
\hline Between groups & 5 & 6651.402 & 1330.280 & 6.715 & .0001 \\
Within groups & 457 & 90535.258 & 198.108 & & \\
TOTAL & 462 & 97186.660 & & & \\
\hline
\end{tabular}




\section{Exploratory regression analysis}

In preparation for regression analysis for exploratory prediction of inventory score, correlation coefficients were calculated between independent variables (educational, age, pregnancy, and mothering experiences) and a dependent variable (inventory scores).

Multicollinearity was present as nine independent variables had correlation coefficients of .65 or higher with another independent variables (Burns \& Grove, 1993). Independent variables that did not demonstrate multicollinearity were academic level, grade point average, breastfed as child, and pregnant now. They were included in the regression equation. Two sets of independent variables demonstrated multicollinearity. The first set was age, ever pregnant, number of children, woman had breastfeed, how long, amount of diet, and own satisfaction. The second set was sister or close friend had breastfed and sister or close friend's satisfaction. One variable from each set was included in the regression equation. These two variables were own breastfeeding satisfaction, sister or close friend's breastfeeding satisfaction. Stepwise multiple regression was preformed to ascertain which variables best predicted inventory and factor scores. A variable entered the stepwise equation based on the largest possible partial correlation (Burns \& Grove, 1993). Of the participants studied, 455 women students had complete data necessary for stepwise regression analysis. Three outliers found through analysis of residuals were included because of sample size. The adjusted R-square was reported to compensate for any overestimation of error (Burns \& Grove, 1993).

For inventory scores, two selected independent variables were significant predictors at the .01 level of significance by exploratory regression analysis. These two were participant's own breastfeeding satisfaction and breastfeeding satisfaction of sister or close friend. Academic level was significant at the .05 level. The adjusted multiple R-square value for the three 
statistically significant predictor variables of inventory scores was .223. This indicated that these three variables explain $22.3 \%$ of the total variance in inventory score. The greatest variance (15.4\%) was explained by own breastfeeding satisfaction level. Breastfeeding satisfaction of sister or close friend explained an additional $6 \%$ of the variance. Academic level explained .9 $\%$ of the variance. All variable coefficients were positively correlated. Table 14 , on page 68 , summarizes the stepwise regression of variables predicting inventory scores.

For the "When" factor, two selected independent variables were significant predictors at the .01 level of significance by exploratory regression analysis. These two were participant's own breastfeeding satisfaction and breastfeeding satisfaction of sister or close friend. The adjusted multiple R-square value for the two statistically significant predictor variables of inventory scores was .139. This indicated that these two variables explain $13.9 \%$ of the total variance in inventory score. The greatest variance $(9.6 \%)$ was explained by own breastfeeding satisfaction level. Breastfeeding satisfaction of sister or close friend explained an additional 3.3 $\%$ of the variance. The variable coefficients were positively correlated. Table 15, on page 69, summarizes the stepwise regression of variables predicting the "When" factor.

For the "How" factor, two selected independent variables were significant predictors at the .01 level of significance by exploratory regression analysis. These two were breastfeeding satisfaction of sister or close friend and participant's own breastfeeding satisfaction. Academic level was significant at the .05 level. The adjusted 
Table 14

Summary of Stepwise Regression for Independent Variables Predicting Inventory Scores $(\mathrm{n}=$ 455)

\begin{tabular}{lccc}
\hline \multicolumn{1}{c}{ Variable } & $\underline{\mathrm{B}}$ & $\underline{\mathrm{SE} \mathrm{B}}$ & Beta \\
Step 1 & & & \\
your satisfaction & 5.882 & .688 & $.395^{* *}$ \\
Step 2 & & & \\
your satisfaction & 5.008 & .681 & $.336^{* *}$ \\
sister satisfaction & 2.618 & .468 & $.256^{* *}$ \\
Step 3 & & & \\
your satisfaction & 4.701 & .689 & $.316^{* *}$ \\
sister satisfaction & 2.389 & .475 & $.234^{* *}$ \\
\hline Rank & & & \\
\hline
\end{tabular}

Note. $\underline{\mathrm{R}}=.154$ for Step 1 ; change $\underline{\mathrm{R}}=.60$ for Step 2; change $\underline{\mathrm{R}}=.009$ for Step $3 \underline{\mathrm{ps}}<.05$ ). $* \mathrm{p}<.05, * * \mathrm{p}<.01$ 


\section{Table 15}

Summary of Stepwise Regression for Independent Variables Predicting the "When" Factor $(\mathrm{n}=$ 455)

\begin{tabular}{lccc}
\hline \multicolumn{1}{c}{ Variable } & $\underline{\mathrm{B}}$ & $\underline{\mathrm{SE} \mathrm{B}}$ & Beta \\
Step 1 & & & \\
your satisfaction & 5.287 & .960 & $.313^{*}$ \\
Step 2 & & & \\
your satisfaction & 5.274 & .962 & $.263^{*}$ \\
sister satisfaction & 3.036 & .661 & $.220^{*}$ \\
\hline
\end{tabular}

Note. $\underline{\mathrm{R}}=.152$ for Step $1 ; \underline{\mathrm{R}}=.227$ for Step $2 ; \underline{\mathrm{R}}=.009$ for Step 3 ps <.05). $* \mathrm{p}<.01$ 
multiple R-square value for the three statistically significant predictor variables of inventory scores was .102 . This indicated that these three variables explain $10.2 \%$ of the total variance in inventory score. The greatest variance $(6.2 \%)$ was explained by breastfeeding satisfaction of sister or close friend .Own breastfeeding satisfaction level explained an additional $3.1 \%$ of the variance. Academic level explained $.9 \%$ of the variance. All variable coefficients were positively correlated. Table 16, on page 71 , summarizes the stepwise regression of variables predicting the "How" factor.

For the "Who" factor, two selected independent variables were significant predictors at the .01 level of significance by exploratory regression analysis. These two were participant's own breastfeeding satisfaction and breastfeeding satisfaction of sister or close friend. Academic level was significant at the .05 level. The adjusted multiple R-square value for the three statistically significant predictor variables of inventory scores was .145. This indicated that these three variables explain $14.5 \%$ of the total variance in inventory score. The greatest variance $(9.5$ $\%$ ) was explained by own breastfeeding satisfaction. Breastfeeding satisfaction of sister or close friend explained an additional $3.3 \%$ of the variance. Academic level point average explained 1.7 $\%$ of the variance. All variable coefficients were positively correlated. Table 17 , on page 72, summarizes the stepwise regression of variables predicting the "Who" factor.

For the What" factor, two selected independent variables were significant predictors at the .01 level of significance by exploratory regression analysis. These two were participant's own breastfeeding satisfaction and breastfeeding satisfaction of sister or close friend. Grade point average was significant at the .05 level. The adjusted multiple R-square value for the three statistically significant predictor variables of inventory scores was .178. This indicated that these three variables explain $17.8 \%$ of the total variance in inventory score. 
Table 16

Summary of Stepwise Regression for Independent Variables Predicting the "How" Factor $(\mathrm{n}=$ 455)

Variable

$\underline{B} \quad \underline{\text { SE B }} \quad$ Beta

Step 1

your satisfaction $\quad 2.381 \quad .459 \quad .253 * *$

Step 2

$\begin{array}{llll}\text { your satisfaction } & 1.974 & .463 & .210 * * \\ \text { sister satisfaction } & 2.577 & .674 & .188 * *\end{array}$

Step 3

\begin{tabular}{cccc} 
your satisfaction & 1.755 & .471 & $.186^{* *}$ \\
sister satisfaction & 2.285 & .683 & $.167^{* *}$ \\
& & & \\
\hline Academic level & .960 & .422 & $.114^{*}$ \\
\hline
\end{tabular}

Note. $\underline{\mathrm{R}}=.062$ for Step 1; change $\underline{\mathrm{R}}=.031$ for Step 2; change $\underline{\mathrm{R}}=.009$ for Step $3 \mathrm{ps}<.05$ ). $* \mathrm{p}<.05, * * \mathrm{p}<.01$ 


\section{Table 17}

Summary of Stepwise Regression for Independent Variables Predicting the "Who" Factor $(\mathrm{n}=$ 455)

\begin{tabular}{cccc}
\hline \multicolumn{1}{c}{ Variable } & $\underline{\mathrm{B}}$ & $\underline{\mathrm{SE} B}$ & Beta \\
Step 1 & & & \\
your satisfaction & 9.161 & 1.403 & $.312^{* *}$ \\
Step 2 & & & \\
your satisfaction & 7.860 & 1.414 & $.268^{* *}$ \\
sister satisfaction & 3.895 & .972 & $.193^{* *}$ \\
Step 3 & & & \\
your satisfaction & 7.067 & 1.426 & $.241^{* *}$ \\
sister satisfaction & 3.301 & .983 & $.164^{* *}$ \\
\hline academic level & 2.605 & .882 & $.144^{*}$ \\
\hline
\end{tabular}

Note. $\underline{\mathrm{R}}=.152$ for Step 1 ; change $\underline{\mathrm{R}}=.227$ for Step 2; change $\underline{\mathrm{R}}=.009$ for Step $3 \underline{\mathrm{ps}}<.05$ ). $* \mathrm{p}<.05, * * \mathrm{p}<.01$ 
The greatest variance $(14.5 \%)$ was explained by own breastfeeding satisfaction level. Breastfeeding satisfaction of sister or close friend explained an additional $2.6 \%$ of the variance. Grade point average explained .7\% of the variance. All variable coefficients were positively correlated. Table 18, on page 74, summarizes the stepwise regression of variables predicting the "Who" factor. For the "Why" factor, two selected independent variables were significant predictors at the .01 level of significance by exploratory regression analysis. These two were participant's own breastfeeding satisfaction and breastfeeding satisfaction of sister or close friend. Breastfeed as a baby was significant at the .05 level. The adjusted multiple R-square value for the three statistically significant predictor variables of inventory scores was .071. This indicated that these three variables explain $7.1 \%$ of the total variance in inventory score. The greatest variance (4\%) was explained by own breastfeeding satisfaction level. Breastfeeding satisfaction of sister or close friend explained an additional $2.1 \%$ of the variance. Breastfed as a baby explained $1 \%$ of the variance. All variable coefficients were positively correlated. Table 19, on page 75 , summarizes the stepwise regression of variables predicting the Why" factor. 
Table 18

Summary of Stepwise Regression for Independent Variables Predicting the "What" Factor (n = 455)

\begin{tabular}{lccc}
\hline \multicolumn{1}{c}{ Variable } & $\underline{\mathrm{B}}$ & $\underline{\mathrm{SE} \mathrm{B}}$ & Beta \\
Step 1 & & & \\
your satisfaction & 7.000 & .847 & $.384^{* *}$ \\
Step 2 & & & \\
your satisfaction & 6.276 & .857 & $.344^{* *}$ \\
sister satisfaction & 2.168 & .589 & $.173^{* *}$ \\
Step 3 & & & \\
your satisfaction & 5.831 & .881 & $.320^{* *}$ \\
sister satisfaction & 2.061 & .589 & $.164^{* *}$ \\
\hline grade point average & 2.857 & 1.403 & $.097^{*}$ \\
\hline
\end{tabular}

Note. $\underline{\mathrm{R}}=.145$ for Step 1 ; change $\underline{\mathrm{R}}=.026$ for Step 2 ; change $\underline{\mathrm{R}}=.007$ for Step $3 \underline{\mathrm{ps}}<.05$ ). $* \mathrm{p}<.05, * * \mathrm{p}<.01$ 
Table 19

Summary of Stepwise Regression for Independent Variables Predicting the "Why" Factor $(\mathrm{n}=$ 455)

\begin{tabular}{lccc}
\hline \multicolumn{1}{c}{ Variable } & $\underline{\mathrm{B}}$ & $\underline{\text { SE B }}$ & Beta \\
Step 1 & & & \\
your satisfaction & 4.583 & 1.092 & $.207^{* *}$ \\
Step 2 & & & \\
your satisfaction & 3.784 & 1.109 & $.171^{* *}$ \\
sister satisfaction & 2.390 & .762 & $.157^{* *}$ \\
Step 3 & & & \\
your satisfaction & 3.974 & 1.106 & $.179^{* *}$ \\
sister satisfaction & 2.358 & .758 & $.155^{* *}$ \\
\hline grade point average & 4.599 & 2.007 & $.111^{*}$ \\
\hline
\end{tabular}

Note. $\underline{\mathrm{R}}=.040$ for Step 1 ; change $\underline{\mathrm{R}}=.021$ for Step 2 ; change $\underline{\mathrm{R}}=.010$ for Step $3 \underline{\mathrm{ps}}<.05$ ). $* \mathrm{p}<.05, * * \mathrm{p}<.01$ 


\section{Chapter 5 \\ DISCUSSION}

The health of babies is promoted by breastfeeding. Women have the ability to breastfeed their babies because of their anatomy and physiology for breast milk production. But many women in the United States do not breastfeed their babies. Three concepts about why women do not initiate breastfeeding are mental organization, cultural beliefs and breastfeeding personal efficacy beliefs. Women who are college educated change mentally (Kegan, 1994) and are more

likely to breastfeed. Women who breastfeed challenge nipplephobia, the cultural undermining of breastfeeding (Friedman, 1998). Breastfeeding personal efficacy beliefs are judgements that provide women with confidence (Bandura, 1992, 1995, 1997) for initiating new behavior. Women judge the likelihood of successful performance of breastfeeding in a wide variety of circumstances. Like The Little Engine That Could (Pitty, 1930), women initiate breastfeeding when they can say, "I think I can, I think I can.” Mastery learning, vicarious learning, symbolic learning and physiological comfort influence personal efficacy beliefs. Personal efficacy beliefs are important in initiation and perseverance of health promotion behavior (Pender, 1996).

This dissertation examined three issues: university women's personal efficacy beliefs about breastfeeding, the reliability and validity of a new research instrument that measures breastfeeding personal efficacy beliefs, and the relationship of academic level to personal efficacy beliefs about breastfeeding. The Breastfeeding Personal Efficacy Beliefs Inventory was designed by the present author to measure women's confidence about initiating breastfeeding and to gather information about the academic, pregnancy and breastfeeding experiences of women. 
The pilot of the initial research instrument conducted with a convenience sample provided evidence of high internal consistency. The personal efficacy belief, breastfeeding, and developmental literature evidenced the content validity of the initial instrument. Construct validity evidence was found in comparison of contrasted groups. Analysis of the pilot data led to a small number of revisions to the inventory.

For this dissertation, the population of university women was sampled randomly. The sample contained women with the same percentages of academic level as found in the population Seven hundred women were mailed the inventory with a cover letter, instructions and $\$ 2$. A satisfactory return rate of $70.6 \%$ was accomplished. The schedule of the spring academic semester influenced data collection. Because of spring break and the examination period, two contacts were accomplished. If four contacts had occurred, the return rate might have been closer to $85 \%$ (Mangione, 1995).

Two problems were identified about the inventory. The first was with the 100 -millimeters long visual analog scale. Each end was anchored with a percentage of confidence and another percentage was in the middle $(0 \%, 50 \%$, and $100 \%)$. Some participants $(7 \%)$ circled $50 \%$ instead of making a mark along the line. If $50 \%$ were not written along the line, a mark would have been forced. Burns \& Grove (1993) suggested a clean 100-millimeter line. The other problem was the indirect measure of academic level. The information obtained from the Student Data Services Office did not contain academic level of each randomly selected student, only the percentages of students in each level. The inventory asked for a number of academic credits completed. Some participants left this space blank. Asking directly for academic level would have been more effective. 
For data analysis, missing data were not replaced. This solution for the missing data problem created its own difficulties, but it promoted the most accurate data analysis. Not replacing data meant, first, that a different combination of items was computed for inventory scores of some participants and, second, that calculation of different statistical methods included different participants, depending on data available. Since the sample size was larger and response rate was higher, the advantage of not replacing data was that as many actual data as possible were used.

For data analysis, the personal efficacy belief item responses were not normally distributed. Distributions of most items were skewed negatively. Most items were distributed in a platykurtic or flattened curve. The distribution of inventory scores met the assumption of normal distribution necessary for various statistical methods. So, inventory score was used for the dependent variable in various statistical methods. Square root or logarithmic transformation of the item responses might have revealed normal distributions.

The university women participants who returned inventories reported academic rank in approximate proportion to the university population. Professional students and freshman had the lowest inventory return rate; graduate students had the highest inventory return rate. Older participants reported greater experience with pregnancy. A few women mentioned pregnancies that were not successful.

From their handwritten comments on the inventory, 129 participants expressed a variety of views about breastfeeding. Written comments expressed views of feminism, male backlash, earth motherhood, lesbian community, ignorance, disinterest and enthusiasm. The most frequent (28\%) comment content written on the inventory was of ignorance. One sophomore student wrote, "This is the first time I heard about this - ever!" The personal efficacy belief item with the 
most handwritten comments was confidence in ability to breastfeed through a growth spurt. The handwritten comments were mostly from lower academic rank students and expressed ignorance about the meaning of growth spurt. This item's purpose was to measure confidence in the ability to manage the "demand controls supply" issue of breast milk production. One woman, a lesbian, asked that partner be used instead of father. The use of father/partner would be appropriate.

The university women participants reported the greatest magnitude of confidence in their ability to get information about breastfeeding. Their academic experience could lead to confidence in ability to seek information. The university women reported less confidence in the ability to pump breast milk at work and save it for baby, to improve baby's intelligence by breastfeeding, to eat mostly as they pleased, to breastfeed for one year, to breastfeed at the mall, and to ease return to work by breastfeeding. They reported the least magnitude of confidence in ability to take most drugs that they needed while breastfeeding.

Evidence of high internal consistency reliability was revealed by Cronbach's alpha. This meant inventory items measured related variables. Although the research instrument is internally consistent, Bandura (1997) warned of danger to the construct validity of personal efficacy belief instruments if internal consistency reliability was too high. He cautioned that the full breath of personal efficacy beliefs be explored.

Evidence for content-related validity was the process of research instrument development. The writings of experts about the growth and development of women guided research instrument development. In addition, research instrument development was guided by the impact of breastfeeding on the lives of mothers, cultural beliefs about breastfeeding, health promotion, and measuring personal efficacy beliefs. 
Construct validity of the inventory was supported in two ways. Factor analysis identified five sub-scales of the 27-item inventory. Six items were efficacy beliefs about "When," or time of breastfeeding. Seven items were efficacy beliefs about "How," or support for and techniques of breastfeeding. Four items were efficacy beliefs about "Who," or breastfeeding with other people present. Six items were efficacy beliefs about "What," or perceived barriers to breastfeeding. Finally, three items were efficacy beliefs about "Why," or advantages of breastfeeding. These factors of the inventory revealed women's confidence about initiating breastfeeding in many circumstances. One-way analysis of variance was the second support of construct validity. One-way analysis of variance revealed groups of women with significantly higher inventory scores than their contrasted groups. Women who had breastfed, who were mothers, and who had higher academic level, scored significantly higher on the inventory. Breastfeeding women demonstrated mastery learning about breastfeeding. Mothers demonstrated mastery learning (Bandura, 1992, 1995, 1997) about child-care and, perhaps, vicarious learning about breastfeeding. Women with increased academic level had different mental organization.

Prediction of inventory scores by exploratory multiple regression analysis was minimally successful. Three independent variables were responsible for less than one-quarter of the inventory score variance. A woman's satisfaction with breastfeeding, a measure of mastery learning, and sister or close friend's satisfaction, a measure of vicarious learning, accounted for most of the explained variance. Academic level, a measure of worldview development, accounted for less than $1 \%$ of the inventory score variance. Most of the explained variance for the five inventory factors, "When," "How," Who," "What," and Why," was explained by a woman's satisfaction with breastfeeding and a woman's sister or close friends satisfaction with breastfeeding. Academic level accounted for less than $1 \%$ of the variance of the "How," and 
"Who" factors. Grade point average accounted for less than $1 \%$ of the "What" factor variance. Being breastfed as a baby accounted for less than $1 \%$ of the "Why" factor variance. Both grade point average and being breastfed as a baby may reflect worldview development.

The findings of this dissertation were, first, the magnitude of women university students' confidence to breastfeed in various circumstances. The women's confidence in their ability to breastfeed in circumstances of perceived difficulties was lowest in magnitude. The women's confidence in their ability to accomplish breastfeeding's advantages and confidence in their ability to breastfeed with other people present were both slightly stronger in magnitude. The women's confidence in their ability to breastfeed for different lengths of time was stronger yet in magnitude. The women's confidence in their ability to do breastfeeding was strongest in magnitude. The next finding was that a positive correlational relationship between three independent variables, academic level, grade point average, and being breastfed as a baby, and inventory scores was supported. but academic level, grade point average and being breastfed as a baby was not predictive of inventory scores. The final finding was initial support for validity and reliability for the inventory. These findings can be applied to women attending this university because the sample was randomly selected and the return rate of was $70.6 \%$.

These findings were an initial step in the process of empirically describing the development of women's personal efficacy beliefs about breastfeeding. The next research process would be to design and test interventions based on these findings to increase symbolic learning of breastfeeding personal efficacy. Symbolic learning is accomplished through verbal persuasion about personal efficacy. Although symbolic learning is less effective in changing personal efficacy beliefs than either mastery learning or vicarious learning, it does not require 
actual breastfeeding. The five factors of breastfeeding personal efficacy beliefs, or confidence, can be the basis for the design of interventions.

Clinically, these findings can be used to promote "I think I can, I think I can (Witty, 1930)." Nursing and other disciplines can apply the factors of personal efficacy beliefs to promote breastfeeding. They can encourage efficacious thinking about ability to breastfeed in circumstances of perceived barriers, such as through a growth spurt, to eat mostly as women please, or to take needed drugs. They can encourage efficacious thinking about ability to improve baby's health and intelligence by breastfeeding. They can encourage efficacious thinking about breastfeeding in the presence of others, such as at the mall or with extended family members present. Nursing and other disciplines can encourage efficacious thinking about breastfeeding for longer lengths of time. They can encourage efficacious thinking about ability to receive support for and learn techniques of breastfeeding. Finally, since university women students with lower academic level have lower magnitudes of personal efficacy beliefs about breastfeeding, the findings can be used to develop and test symbolic learning interventions about breastfeeding personal efficacy for health education for university and younger students.

For broader generalization of the findings, additional studies should be conducted with the inventory to describe the development of women's breastfeeding personal efficacy beliefs. These should include replications of this study and tests with populations from other universities or across universities. Studies should be designed to increase the ability to predict inventory scores of university women from independent variables. Then, a model of personal efficacy belief development should be tested. In addition, the personal efficacy belief item list should be tested for appropriate inclusiveness with different populations of women. The inventory items should be tested with culturally and educationally diverse populations of women. Evidence of the 
predictive nature of the inventory should be established. To begin establishing the predictive nature of the inventory, participants of this dissertation could be located through alumni services and restudied in three to five years. Successive validity should be established over time. 


\section{References}

Allison, D.M. (1994). Less-conscious values decision making in Afro-American women concerning infant feeding choice. Dissertation Abstracts International, 55-05A, 1220.

American Academy of Pediatrics and The American College of Obstetricians and Gynecologists. (1992). Maternal and newborn nutrition. In: Guidelines for perinatal care, ( $^{\text {rd }}$ Ed). Elk Grove Village, IL: AAP 1992:181.

American Academy of Pediatrics, Committee on Drugs. (1994). The transfer of drugs and other chemicals into human milk. Pediatrics, 84, 924-36.

Ball, T.M., \& Wright, A.L. (1999). Health care costs of formula-feeding in the first year of life. Pediatrics, 103, 870-876.

Bandura, A. (1992). Exercise of personal agency through the self-efficacy mechanism. In R. Schwarzer (Ed.), Self-efficacy: Thought control of action (pp.3-37). Washington, DC: Hemisphere.

Bandura, A. (1995). Self-efficacy in changing societies. New York: Freeman.

Bandura, A. (1997). Self-efficacy: The exercise of control. New York: Freeman.

Bar-Yam, M. (1991). Do women and men speak in different voices? A comparative study of self-evolvement. International Journal of Aging and Human Development, 32, 247-259.

Baunslag, N., \& Micheals, D. (1995). Milk, money and madness: The culture and politics of breastfeeding. Westport, CT: Bergin \& Garvey.

Belenkey, M.F., Clinchy, B.M., Goldberger, N., \& Tarule, J.M. (1986). Women's ways of knowing: The development of self, voice, and mind. New York: Basic Books.

Betz, N. (1992). Counseling uses of career self-efficacy theory. The Career Development Quarterly, 41, 22-26.

Bouffard-Bouchard, T. (1990). Influence of self-efficacy on performance in a cognitive task. Journal of Social Psychology, 130, 353-363.

Bove, C. F. (1996). Sociocultural environments and "ways of knowing" as breast feeding determinants in socioeconomically disadvantaged women. Dissertation Abstracts International, 51-01B, 247.

Briggs-Myers, I. (1980). Introduction to type. Palo Alto, CA: Consulting Psychologists. 
Buczynski, P. L. (1993). The development of a paper-and-pencil measure of Belenkey, Clinchy, Goldberger and Tarule's (1986) conceptual model of women's-ways- of-knowing instrument. Journal of College Student Development, 34, 117-200.

Burglehaus, M.J., Smith, L.A., Sheps, S.B., \& Green, L.W. (1997). Physicians and breastfeeding: Beliefs, knowledge, self-efficacy and counseling practice. Canadian Journal of Public Health, 88, 383-387.

Burns, N., \& Grove, S. (1993). The practice of nursing research: Conduct, critique \& utilization. $\left(2^{\text {nd }}\right.$ Ed) Philadelphia: Saunders.

Chezem, J., Friesen, C., Montgomery, P. Fortman, T., \& Clark, H. (1998). Lactation duration: Influences of human milk replacements and formula samples on women planning postpartum employment. Journal of Obstetrical, Gynecological and Neonatal Nursing, 26, 646651.

Cleveland, A. P. (1999). Personal efficacy beliefs about breastfeeding. International Journal of Childbirth Education, 14 (3), 30-35.

Coreil, J., Bryant, C. Westover, B., \& Baily, D. (1995). Health professionals and breast feeding counseling: Client and provider views. Journal of Human Lactation, 11, 265-271.

Covington, M., \& Omelich, C (1992). The influence of expectancies and problemsolving strategies on smoking intentions. In Schwarzer (Ed.), Self-efficacy: Thought control of action. Washington, DC: Hemisphere.

Cunningham, A. (1995). Breastfeeding: Adaptive behavior for child health and longevity. In P. Stuart-Macadam and K. Dettwyler (Eds.), Breastfeeding: Biocultural Perspectives, (pp. 243-264). New York: Gruyter.

Dennis, C. (1999). Theoretical underpinnings of breastfeeding confidence: A selfefficacy framework. Journal of Human Lactation, 15, 195-201.

Dewey, K.G. (1995). Growth of breast-fed infants deviates from current reference data: A pooled analysis of US, Canadian, and European data sets. Pediatrics, 96, 495-503.

Dewey, K. G., Heinig, J., \& Nommsen-Rivers, L. A. (1995). Differences in morbidity between breastfed and formula-fed infants. Journal of Pediatrics 126, 697-702.

Dettwyler, K. (1995). Beauty and the breast: The cultural context of breastfeeding. In P. Stuart-Macadam \& K. Dettwyler (Eds.), Breastfeeding: Biocultural Perspectives. New York: Gruyter.

Dillion, A. (1997). Drug therapy in the nursing mother. Obstetrics and Gynecological Clinics of North America 24, 675-696. 
Droegkamp, J., \& Taylor, K. (1995). Prior leaning assessment: Critical self-reflection, and reentry woman's development. New Directions for Adult and Continuing Education, 65, 2936.

Drummond, J., \& Rickwood, D. (1997). Childbirth confidence: Validating the childbirth self-efficacy inventory (CBSEI) in an Australian sample. Journal of Advanced Nursing, 26, 613622.

Duffy, L.C., Faden, H., Wasielewski, R., Wolf, J.,\& Krystofik, D. (1997). Exclusive breastfeeding protects against bacterial colonization and day care exposure to otitis media. Pediatrics, 100, E7.

Duncan, J. (1993). Exclusive breastfeeding for at least 4 months protects against otitis media Pediatrics 91, 867-72.

Elkind, D. (1974). Children and adolescents: Interpretive essays on Jean Piaget. New York: Oxford.

Elkind, D. (1976). Child Development and education: A Piagetian perspective. New York: Oxford.

Elkind, D. (1981). The hurried child: Growing up too fast too soon. Reading, MA: Addison-Wesley.

Elkind, D. (1987). Miseducation: Preschoolers at risk. New York: Alfred A. Knopf.

Erikson, E.R. (1963). Childhood and society. ( $2^{\text {nd }}$ ed). New York: Norton.

Fawzi, W. (1997). Maternal anthropometry and infant feeding practices in Israel in relation to growth in infancy: the North African Infant Feeding Study. American Journal of Clinical Nutrition 65, 1731-1737.

Fink, A. (1995). How to sample in surveys. Thousand Oaks, CA: Sage.

Fishbein, M., Bandura, A., \& Trandis, H. (1991). Factors influencing behavior and behavior change: Final report of theorist's workshop on AIDS-related behavior. Washington, DC: October, 3-5, 1991. National Institute of Mental Health, National Institutes of Health.

Fly, A.D., Uhlin, K.L., \& Wallace, J.P. (1998). Major mineral concentrations in human milk do not change after maximal exercise testing. American Journal of Clinical Nutrition, 68 , 345-349.

Freud, S. (1969). An outline of psycho-analysis. New York: Norton.

Friedman, D. (1998). Nipplephobic? Birth Gazette, 14(2), 26-29. 
Frye, E. (1977). Fry's readabiltiy graph: Clarification, validity and extension to level 17. Journal of Reading, 21, 242-252.

Garcia, A., Norton-Broda, M., \& Frenn, M. (1995). Gender and developmental differences in exercise beliefs among youth and prediction of their exercise behavior. Journal of School Health, 65, 213-219.

Gilligan, C. (1982). In a different voice. Cambridge: Howard University.

Goldberger, N., Tarule, J., Clinchy, B., \& Belenky, M. (1996). Knowledge, difference, and power. New York: Basic Books.

Goldman, A. (1993). The immune system of human milk antimicrobial, antiinflammatory and immunomodulating properties. Pediatric Infectious Disease Journal 12, 664-671.

Greiner, T. (1996). The concept of weaning: Definitions and their implications. Journal of Human Lactation 12, 123-128.

Harkless, G. (1991). Investigating intention to breast feed: Applying the Triandis Model of social behavior. Unpublished manuscript, Boston University. $37-42$.

Hattori, R., \& Hattori, H. (1999). Breastfeeding twins: Guidelines for success. Birth, 26,

Holman, H. \& Lorig, K. (1990). Perceived self-efficacy in self-management of chronic disease. In R. Schwarzer (Ed.), Self-efficacy: Thought control of action (pp.305-323). Washington, DC: Hemisphere.

Horan, M., Kim, K., Gendler, P., Froman, R., \& Patel, M. (1998). Development and evaluation of the osteoporosis self-efficacy scale. Research in Nursing \& Health, 21, 395-403.

Horney, K. (1950). Neurosis and human growth: The struggle toward self-realization. New York: Norton.

Horwood, L.J., \& Fergusson, D.M. (1998). Breastfeeding and later cognitive and academic outcomes. Pediatric, 101, E9.

Hosfstetter, C., Hovell, M., \& Sallis, J. (1990). Social leaning correlates of exercise selfefficacy: Early experiences with physical activity. Social Science and Medicine, 31, 1169-1176.

Howard, C.R., Howard, F,M., Lanphear, B., deBlieck, E.A. Eberly, S, \& Lawrence, R.A. (1999). The effects of early pacifier use on breastfeeding duration. Pediatrics, 103, E33.

Humphreys, A.S., Thompson, N.J., \& Miner, K.R. (1998). Intention to breastfeed in lowincome pregnant women: The role of social support and previous experience. Birth, 25, 169174. 
Izatt, S. (1997). Breastfeeding counseling by health care providers. Journal of Human Lactation, 13, 109-113.

Jordan, P.L. \& Wall, V.R. (1990). Breastfeeding and fathers: Illuminating the darker side. Birth, 17, 210-213.

Jung, K. (1965). Dreams, memories, reflections. New York: Vintage.

Kegan, R. (1982). The evolving self: Problem and process in human development. Cambridge, MA: Harvard.

Kegan, R., (1994). In over our heads: The mental demands of modern life. Cambridge, MA: Harvard.

Kegan, R, Lahey, L., \& Souvaine, E. (1998). From taxonomy to ontogeny: Thoughts on Loevinger's theory in relation to subject-object psychology. In P. Westenberg, A. Blasi, \& L. Cohn (Eds.), Personality Development: Theoretical, Empirical, and Clinical Investigations of Loevinger's Conception of Ego Development, Mahwah, NJ: Lawrence Erlbaum.

Kessler, L.A., Gielen, A.C., Diener-West, M., Paige, D.M. (1995). The effect of a woman's significant other on her breastfeeding decision. Journal of Human Lactation, 11, 103109.

Kolb, D.A. (1980). The adaptive style inventory. Cleveland: David Kolb.

Kohlberg, L. (1976). Moral stages and moralization: The cognitive developmental approach. In T. Lickona (Ed.) pp.31-53, Moral development and behavior. New York: Holt, Reinhart, \& Winston.

Kovach, A. (1997). Hospital breastfeeding policies in the Philadelphia area: a comparison with the Ten Steps to Successful Breastfeeding. Birth, 24, 41-48

Labbok, M., \& Krosovec, K. (1990). Toward consistence in breast feeding definitions. Birth, 17, 226.

Lawrence, R. (1994). Breastfeeding: A guide for the medical profession. $\left(4^{\text {th }}\right.$ ed.). St. Louis: Mosby.

Litt, M. (1988). Self-efficacy and perceived control: Cognitive mediators of pain tolerance. Journal of Personality and Social Psychology, 54, 149-160.

Locklin, M.P. (1995). Telling the world: Low income women and their breastfeeding experiences. Journal of Human Lactation, 11, 285-291. 
Long, D., Funk-Archuleta, M., Geiger, C., Mozar, A., \& Heins, J. (1995). Peer counselor program increase breast feeding rates in Utah Native American WIC population. Journal of Human Lactation, 11, 279-284.

Lucas, A., Morley, R., Cole, T., Lister, B., \& Leeson-Payne, C. (1992).Breast milk and subsequent intelligence quotient in children born preterm. The Lancet, 339, 261-264.

Mangione, T. (1995). Mail surveys: Improving the quality. Thousand Oaks, CA: Sage.

Marienau, C. (1995). In their own voices: Women learning about their own development. New Directions For Adult and Continuing Education, 65, 37-44.

McAuley, E. (1992). The role of efficacy cognitions in the prediction of exercise behavior in middle-aged adults. Journal of Behavioral Medicine, 15, 65-88.

Marquis, G., Habicht, J., Lanata, C., Black, E., \& Rasmussen, K. (1997). Breast milk or animal-product foods improve linear growth of Peruvian toddlers consuming marginal diets American Journal of Clinical Nutrition, 66, 1102-1109.

Mathur, G. (1993). Breastfeeding and childhood cancer. Indiana Pediatrics, 30, 51-657.

Mayer, E. (1988). Reduced risk of IDDM among breastfed children. Diabetes 37, 162532.

McMillian, J., \& Schumacher, S. (1997). Research in education: A conceptual introduction. New York: Addison Wesley.

Mitchell, J. (1977). Psycho-analysis and feminism. New York: Vintage Books.

Moon, J., \& Humenick, S. (1989). Breast engorgement: contributing variables and variables amenable to nursing intervention. Journal of Gynecological and Neonatal Nursing 18, 309-315.

Morrow, A.L., Guerrero, M.L., Shults, J., Calva, J.J., Lutter, C., Bravo, J., Ruiz-Palacios, G., Morrow, R.C., \& Butterfoss, F.D. (1999). Efficacy of home-based peer counseling to promote exclusive breastfeeding: A randomized controlled trial. Lancet, 353, 1226-1231.

Mozingo, J.N. (Feb., 1996). Empowering women to breastfeed. Advance for Nurse Practitioners, 5, 43-46, 65.

O’Campo, P., Faden, R.R., Gielen, A.C., \& Wang, M.C. (1992). Prenatal factors associated with breastfeeding duration: Recommendations for prenatal interventions. Birth, 19, 195-201.

Oxby, H. (1994). When do women decide? Health Visit, 67, 161. 
Pender, N. (1996), Health promotion in nursing practice. $\left(3^{\text {rd }}\right.$ Ed). Stamford, CT: Appleton \& Lange.

Pender, N., Walker, S, \& Sechrist, K. (1990). The health promotion model: Refinement and validation. Final Report to the National Center for Nursing Research, National Institutes of Health (grant no. SN01121) Dekalb IL: Northern Illinois University.

Perry, W.G. (1968). Forms of intellectual and ethical development in the college years: A scheme. Troy, MO: Holt, Rinehart, \& Winston.

Piaget, J. (1966). The psychology of the child. New York: Harper Torchbooks.

Piaget, J. (1968). Six psychological studies. New York: Vintage Books.

Pitty, W. (1930). The little engine that could. New York: Platt \& Munk.

Prusia, G., \& Kinicki, A. (1996). A motivational investigation of group effectiveness using social cognitive theory. Journal of Applied Psychology, 81, 187-198.

Purnell L., \& Counts, M. (1998). Appalachians. In L. Purnell and B. Paulanka (Eds.), Transcultural Health Care (pp. 107-133). Philadelphia, PA: Davis.

Purtell, M. (1994). Teenage girl's attitudes to breastfeeding. Health Visit, 67, 156.

Rajan, L. (1993). The contribution of professional support, information and consistent correct advice to successful breast feeding. Midwifery, 9, 197-207.

Rapheal, D. (1976). The tender gift: Breastfeeding. New York: Schocken.

Riordan, J., \& Auerbach, K. (1999). Breastfeeding and human lactation, $\left(2^{\text {nd }}\right.$ ed). Boston: Jones \& Bartlett.

Riordan, J.M. (1997). The cost of not breastfeeding: a commentary. Journal of Human Lactation , 13, 93-7.

Rogan, W., \& Gaden, B. (1993). Breast-feeding and cognitive development. Early Human Development, 31, 118 and 193.

Ryan, A. S. (1991). Recent declines in breastfeeding in the United States, 1984-1989. Pediatrics 88:719-727. E12.

Ryan, A.S. (1997). The resurgence of breastfeeding in the United States. Pediatrics, 99 ,

Sable, M.R. \& Patton, C.B. (1998). Prenatal lactation advice and intention to breastfeed: Selected maternal characteristics. Journal of Human Lactation, 14, 35-40. 
Schanler, R.J., O’Connor, K.G., \& Lawrence, R.A. (1999). Pediatricians’ practices and attitudes regarding breastfeeding promotion. Pediatrics, 103, E35.

Schwarzer, R. (1992). Self-efficacy in the adoption and maintenance of health behavior: Theoretical approaches and a new model. In R. Schwarzer (Ed.), Self-efficacy: The thought control of action (pp. 217-243). Washington, DC: Hemisphere.

Scott, J.A., \& Binns, C. W. (1999). Factors associated with the initiation and duration of breastfeeding: a review of the literature. Breastfeeding Review, 7, 5-16.

Shepherd, C.K., Power, K.G., \& Carter, H. (1998). Characteristics of responders and nonresponders in an infant feeding study. Journal of Public Health Medicine, 20, 275-80.

Sherer, M., Maddux, J., Mercandante, B., Prectice-Dunn, L., Jacobs, B., \& Rogers, R. (1982). The self-efficacy scale: Construction and validation. Psychological Reports, 51, 663671.

Silfverdal, S.A., Bodin, L., \& Olcen, P. (1999). Protective effect of breastfeeding: an ecologic study of Haemophilus influenzae meningitis and breastfeeding in a Swedish population. International Journal of Epidemiology, 28, 152-156.

Smith, L., (1995). A score sheet for evaluating breastfeeding educational materials. Journal of Human Lactation, 11, 307-311.

Spangler, A. (1999). The United States Breastfeeding Committee continues to evolve. International Lactation Consultant Association: Globe, 7 (3): 10.

SPSS Base 8.0 (Computer Software). (1998). Chicago: SPSS, Inc.

Stanton, A. (1996). Reconfiguring teaching and knowing in the college classroom. In N. Goldberger, J. Tarule, B. Clinchy, \& M. Belenky, Knowledge, difference, and power. (1996). New York: Basic Books.

Sullivan, H.S. (1953). The interpersonal theory of psychiatry. New York: Norton.

Taylor, K., \& Marienau, C. (1995). Bridging practice and theory for women's adult development. New Directions in Adult and Continuing Education, 65, 5-12.

Tempoury, M., Otero, A., Polanco, I.., \& Arribas, E. (1994). Influence of breast-feeding on the infant's intellectual development. Journal of Pediatric Gastroenterology and Nutrition, 18, 32-36.

Taylor, K. \& Marienau, C. (1995). Bridging practice and theory for women's adult development. New Directions for Adult and Continuing Education. 65, 5-12. 
United States Department of Health and Human Services, Public Health Service: Promoting health/preventing disease: Objectives for the nation. Washington: US Government Printing Office, 1980.

United States Department of Health and Human Services. (1990). Healthy people 2000: National health promotion and disease prevention objectives. (DHHS publication No. 91-50213). Washington, DC: Government Printing Office.

Van Popple \& Estok. (1994). Infant feeding choice and adolescent mothers. Journal of Obstetrical, Gynecological and Neonatal Nursing, 13, 115-118.

World Health Organization. (1989). Protecting, promoting and supporting breast-feeding: The special role of maternity services. Geneva, Switzerland: WHO.

Wambach, K.A. (1998). Maternal fatigue in breastfeeding primiparae during the first nine weeks postpartum. Journal of Human Lactation, 14, 219-29.

Wilson, A.C., Forsyth, J., Greene, S.A., Irvine, L., Hau, C., \& Howie, P.W. (1998). Relation of infant diet to childhood health: seven year follow up of cohort of children in Dundee infant feeding study. Breast Milk Journal, 316, 21-25.

Wong, D. L. (1999). Nursing care of infants and children. $\left(6^{\text {th }}\right.$ ed). St. Louis: Mosby.

Wright, A.L., Bauer, M., Naylor, A., Sutcliffe, E., \& Clark, L. (1998). Increasing breastfeeding rates to reduce infant illness in the community level. Pediatrics, 101, 837-44.

Youngkin, E. Q., \& Davis, M.S. (1994). Women's health: A primary care clinical guide. Norwalk, CN: Appleton \& Lange.

Zimmerman, D. (1999). You can make a difference: Increasing breastfeeding rates in an inner-city clinic. Journal of Human Lactation, 15, 217-220. 


\section{Appendix}

\section{Cover Letter}

Dear Participant,

I am a nurse who is interested children's health. Please help me by answering some questions. The enclosed $\$ 2$ is a token of my thanks.

My study is about women's confidence related to breastfeeding. Please mail in your answers, whether or not you are interested in breastfeeding. Your answers will help encourage healthy children, a great resource.

You have been randomly selected to participate in my dissertation study. Your participation is entirely voluntary and you do not have to respond to every item or question.

Your responses will remain anonymous and confidentiality will be maintained.

As a WVU student, neither your class standing, athletic status, or grades will be affected by refusing to participate.

Instructions for completing the questions are on the back of this page.

Thank you for your time and effort,

Ann Cleveland, MSN, RN

Lecturer, WVU 


\section{Instructions}

Each item on the Inventory of Breastfeeding Personal Efficacy Beliefs is a statement about a task. A line showing a scale from $0 \%$ to $100 \%$ follows the statement.

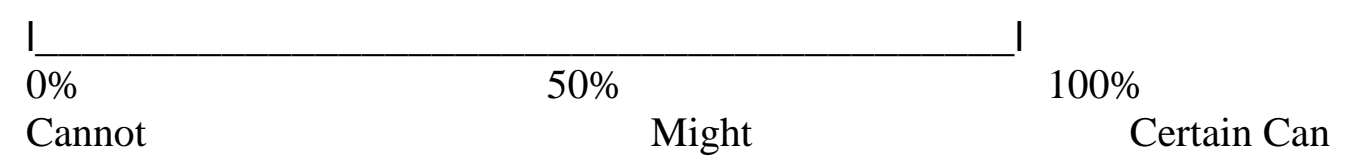

After you read the item, please make a mark along the line that represents how certain you are today about your capability to do the task. Here is an example.

EXAMPLE:

I can answer most questions that my friends ask about baby care.

$\begin{array}{llr}1 & & \\ 0 \% & 50 \% & \\ \text { Cannot } & 50 \% & \text { Certain Can }\end{array}$

Here is how I make my mark. Because I have been studying baby care for a while, I know many but not all answers. I am more than $50 \%$ certain I can answer baby care questions, but I am not $100 \%$ certain I can answer them. So I make my mark like this:

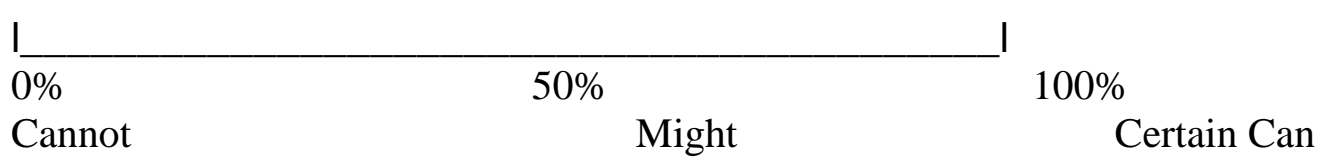

YOU TRY IT! Remember the scale is from 0 to 100 . Your mark can be anywhere along the line.

I can answer most questions that my friends have about baby care:

\begin{tabular}{lcc}
\hline & & \\
$0 \%$ & $50 \%$ & $100 \%$ \\
Cannot & Might & Certain Can
\end{tabular}

Now you are ready to begin! 


\section{Inventory of Breastfeeding Personal Efficacy Beliefs}

\section{Please mark your current level of confidence as if you had a newborn baby.}

1. I can improve my baby' health by breastfeeding

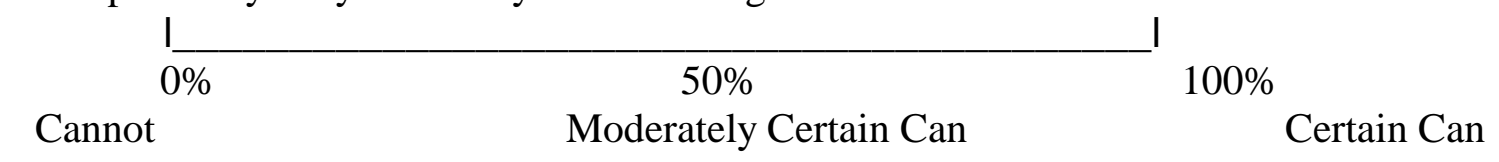

2. I can get information about breastfeeding if I want it.

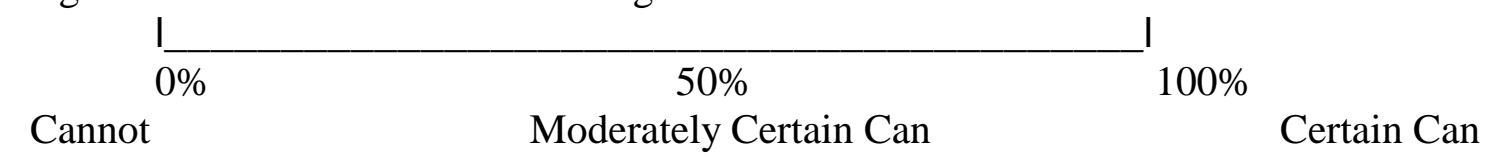

3. I can breastfeed my baby at the mall.

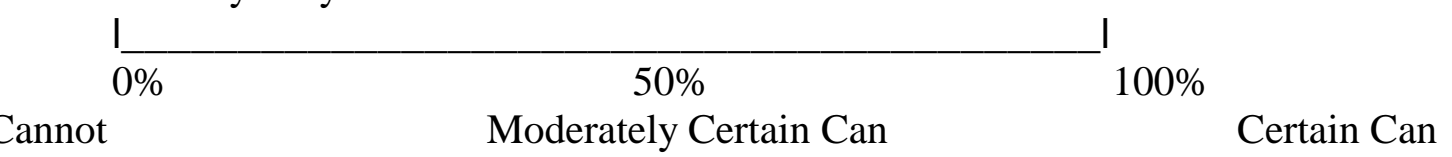

4. I can breastfeed my baby with extended family present.

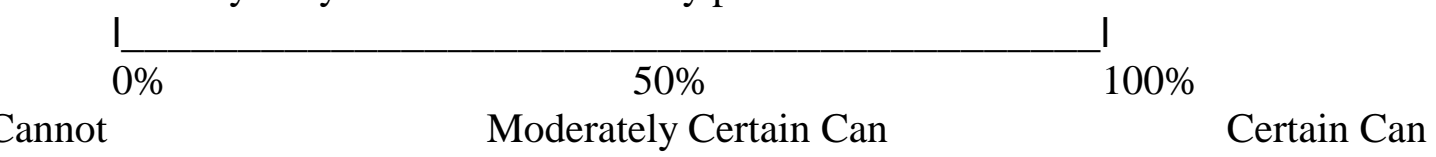

5. I can breastfeed my baby with immediate family members present.

$\begin{array}{lccc}\mathrm{l} & & \\ & & & \\ \text { Cannot } & 50 \% & 100 \% & \\ \text { Moderately Certain Can } & & \text { Certain Can }\end{array}$

6. I can pump breast milk at work and save it for my baby.
I
Cannot
$50 \%$
Moderately Certain Can
Certain Can

7. I can breastfeed my baby through a growth spurt.

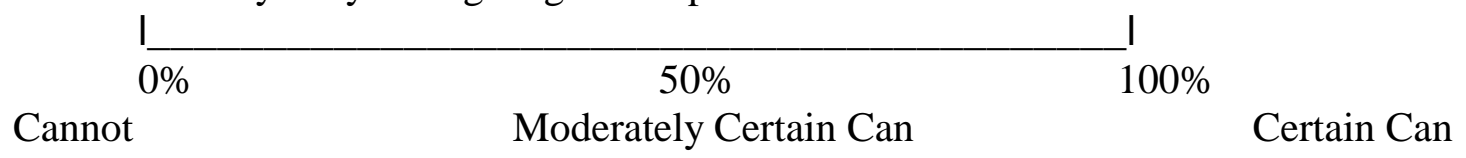

8. I can make enough milk no matter the size of my breast.

\begin{tabular}{cccc}
\multicolumn{1}{l}{$\begin{array}{l}\mathrm{l} \\
\mathrm{C}\end{array} \mathrm{Cannot}^{\text {Moderately Certain Can }}$} & $100 \%$ & \\
& & Certain Can
\end{tabular}

9. I can have an attractive body while I breastfeed.
I
Cannot
$\%$
$50 \%$ $100 \%$
Moderately Certain Can
Certain Can 


\section{Inventory of Breastfeeding Personal Efficacy Beliefs - page two}

Please mark your current level of confidence as if you had a newborn baby.

10. I can learn to get my baby on and off the breast.

$\begin{array}{ccc}\text { Moderately Certain Can } & 50 \% & \\ \text { Cannot } & \text { Modertain Can }\end{array}$

11. I can make milk that is safe for my baby.

$\begin{array}{ccc}\mathrm{l} & 50 \% & \\ \text { Cannot } & \text { Moderately Certain Can } & \\ & \text { Certain Can }\end{array}$

12. I can eat mostly as I please while breastfeeding.

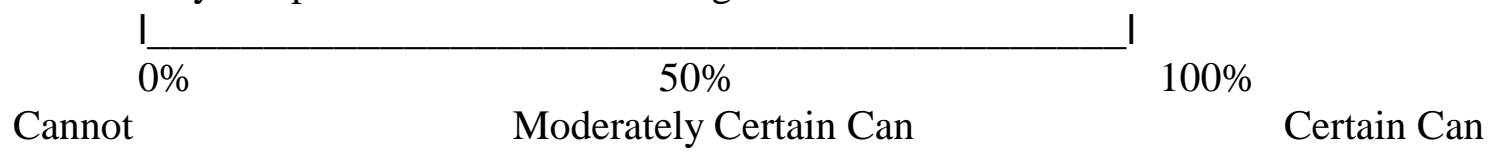

13. I can get help caring for my baby from others while breastfeeding.

$\begin{array}{ccc}1 & & \\ \text { Cannot } & 50 \% & 100 \% \\ \text { Moderately Certain Can } & \text { Certain Can }\end{array}$

14. I can expect support from my baby's father for breastfeeding.

$\begin{array}{ccc}\mathrm{l} & & \\ \text { Cannot } & 50 \% & 100 \% \\ \text { Moderately Certain Can } & \text { Certain Can }\end{array}$

15. I can improve my baby's intelligence by breastfeeding.

$\begin{array}{ccc}\mathrm{l} & & \\ \mathrm{C} & 50 \% & 100 \% \\ \text { Cannot } & \text { Moderately Certain Can } & \text { Certain Can }\end{array}$

16. I can have a pleasant experience while breastfeeding.
$\frac{1}{0 \%}$

Cannot Moderately Certain Can Certain Can

17. I can breastfeed my baby during the nighttime.

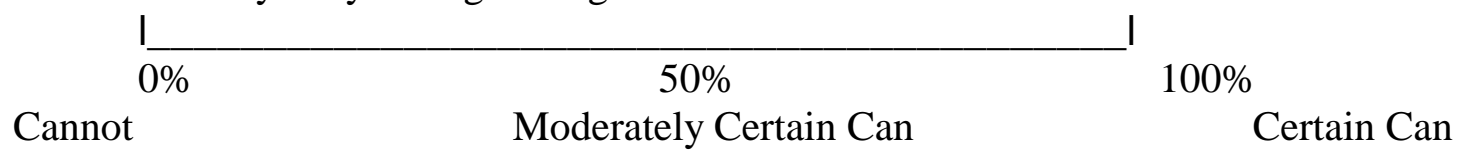

18. I can save money by breastfeeding.

$\begin{array}{ccc}\mathrm{l} & & \\ \text { Cannot } & 50 \% & 100 \% \\ \text { Moderately Certain Can } & \text { Certain Can }\end{array}$




\section{Inventory of Breastfeeding Personal Efficacy Beliefs - page three}

Please mark your current level of confidence as if you had a newborn baby.

19. I can take most drugs that I need while breastfeeding.
I
$50 \%$
$100 \%$
Cannot
Moderately Certain Can
Certain Can

20. I can bond easily with my baby while breastfeeding.
I
$50 \%$
$100 \%$
Cannot
Moderately Certain Can
Certain Can

21 . I can ease my return to work by breastfeeding.
I

$0 \%$

\section{Cannot}

ost activities while breastfeeding,

$\mathrm{I}$
$0 \%$
Moderately Certain Can

Cannot Moderately Certain Can

$100 \%$

Certain Can

23. I can provide all my baby's food for several months by breastfeeding.
I
$50 \%$
$100 \%$
Cannot
Moderately Certain Can
Certain Can

24. I can breastfeed my baby right after birth.
I $0 \%$ $50 \%$ $100 \%$
Cannot Moderately Certain Can
Certain Can

25. I can breast feed my baby for three months.
1 $0 \%$ $50 \%$
$100 \%$
Cannot
Moderately Certain Can
Certain Can

26. I can breast feed my baby for six months.$$
\text { I }
$$$$
0 \%
$$
Cannot
$50 \%$
$100 \%$
Moderately Certain Can
Certain Can

$\%$

27. I can breast feed my baby for one year.

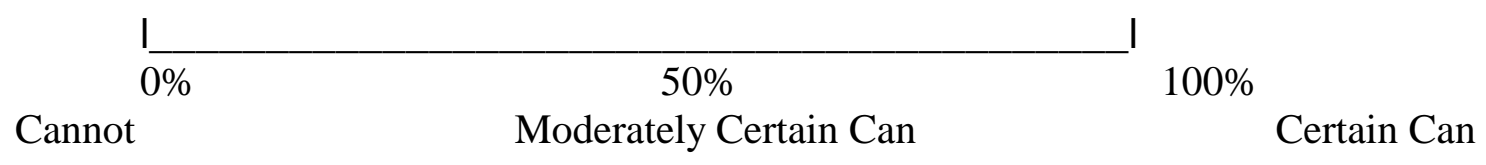




\section{Inventory of Breastfeeding Personal Efficacy Beliefs - page four}

28. Do you have any comments or suggestions about the inventory?

29. What is your age?

30. How many college credits have you earned (courses completed)?

31 . What is your grade point average?

32. Have you decided on a major? No Y Yes

33. If so, which major have you chosen?

34. What is the occupation of your spouse or parent?

35. Were you breastfed as a baby?

No

Yes

Don't know

36. Have you ever been pregnant?

No

Yes

37. Are you pregnant now?

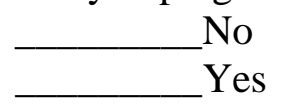

38. If you have children, how many do you have?

None

One

Two If more than two, how many?

39. Has a sister or close friend breastfed?

No

Yes 40. How satisfied was she? (circle one) Low Medium High

41. Have you ever breastfed?

No

Yes

42. How long did you breastfeed?

43. During the early weeks, how much of your baby's diet did you supply?

(Circle one) Full High Medium Low Token

44. How satisfied were you with breastfeeding?

$$
\text { (circle one) Low Medium High }
$$




\section{CURRICULUM VITAE}

Name:

Birthplace:

Citizenship:

Business Address:

Telephone:

Electronic Mail:

Home Address:

Telephone:

1963-1965

1965-1967

1968-1969

1971-1973

1973

1978-1979

1991-1993

1993-present
Ann Pollard Cleveland

Oakland, California

U.S.A.

Department of Health Promotion/Risk Reduction

School of Nursing, West Virginia University

P.O. Box 9630

Morgantown, West Virginia 26506

(304) 293-1398

FAX: (304) 347-1346

acleveland@hsc.wuv.edu

129 Tyrone Road

Morgantown, West Virginia 26508

(304) 594-3556

\section{EDUCATION}

Mary Washington College of the University of Virginia

Pre-Nursing, 1963-1965

University of Virginia

BSN, 1967

University of Wisconsin

Graduate work in pediatric nursing (Professor Florence Blake)

University of Virginia

MSN in pediatric nursing, 1973 (Professor Barbara Brodie)

Masters Thesis (unpublished), 1973

"Social Changes in Adolescent Males with Spinal Cord Injuries"

Non-degree seeking student (15 credits)

School of Education

University of Virginia

Non-degree seeking student

College of Human Resources and Education

West Virginia University

Doctoral degree seeking student

Educational Psychology (Professor Anne Nardi)

College of Human Resources and Education

West Virginia University

NURSING LICENSE：WV\#043371

\section{ACADEMIC APPOINTMENTS AND POSITIONS}

1973-1975

Instructor

School of Nursing

University of Virginia 
1975-1979

1991-2000

2000-2001
Assistant Professor

University of Virginia

Lecturer (Visiting Instructor, 1992-1995)

School of Nursing

West Virginia University

Assistant Professor

School of Nursing

West Virginia University

\section{SCHOLARLY ACTIVITIES AND RESEARCH}

Cleveland, A.P. (1999). Personal efficacy beliefs about breastfeeding. International Journal of Childbirth Education, 14 (3), 30-35.

Pollard, A., Ellingwood, G., Markwood, K., Norville, D., \& Pryer, A. (1985). School and the child with cancer: A program to assist school personnel. JAPON, 2, 7-10.

\section{HONORS}

1998

1982

1972

1967

1996-2000

1974-2000

$1974-1994 / 1998-2000$
President, Beta Kappa Chapter, Sigma Theta Tau, Int. 25th Anniversary Celebration Virginia Division of American Cancer Society, "When Your Student Has Cancer," a National ACS Citation Winner Charter Member, Beta Kappa Chapter of Sigma Theta Tau Lynchos Society of the University of Virginia (Women's Honor Society)

\section{PROFESSIONAL ORGANIZATIONS}

International Lactation Consultant Association

Sigma Theta Tau, International

Dual membership (Beta Kappa and Alpha Roe) (1991-1998)

Finance Committee of Beta Kappa Chapter (1984-1987)

Member, Finance Committee of Beta Kappa Chapter (1982-1984)

Chairman, Bylaws Committee of Beta Kappa (1981-1982)

Research Workshop Committee of Beta Kappa (1980-1981)

Chairman, Finance Committee of Beta Kappa Chapter (1977-1978)

Counselor of Beta Kappa of Beta Kappa (1977-1979)

President of Beta Kappa Chapter (1975-77)

Chairman, Publicity Committee (1974-1975)

American Nurses Association (tri-level)

Member, District V, WVNA (1998-2000)

Council of Clinical Nurse Specialists, VNA (1980-1987) 
$1979-1987$

1975-1979

1990-1991

1989-1990

Missouri

1987-1988 (part-time)

1979-1987

1972 (part-time)

$1970-1972$

$1969-1970$

1967-1969

Summer 1967
Vice President and Program Committee Chairman, District VII

Member, District VII, VNA (1974-1994)

President, District VII, VNA (1985-1987)

Chairman, Publicity Committee, District VII, VNA (1974-1975)

Association of Pediatric Oncology Nurses

Nominations Committee $(1980,1982)$

NAPNAP (National Association of Pediatric Nurse

Associates and Practitioners)

\section{PROFESSIONAL NURSING POSITIONS}

Staff Nurse, Orthopedics and Pediatrics

Monongalia General Hospital

Morgantown, WV

RN Consultant

Gingerbread House for Severely Disabled, Inc. Rolla,

Home Health Nurse, Maternal/Child Division

INOVA Home Health Service

Springfield, Virginia

Clinical Nurse Specialist for Pediatric Oncology

Division of Nursing

University of Virginia Medical Center

Assistant Professor of Nursing

University of Virginia

Staff Nurse

Children's Rehabilitation Center

Charlottesville, Virginia

Public Health Nurse

Fairfax County Health Department

Fairfax, Virginia

Head Nurse, Pediatric Specialty Clinics

University of Wisconsin Hospitals

Madison, Wisconsin

Staff Nurse, Obstetrical Unit (Labor and Delivery,

Newborn, Nursery, and Postpartum)

University of Wisconsin Hospitals

Madison, Wisconsin

Staff Nurse, Surgical Unit

Sibley Memorial Hospital

Washington, DC 


\section{SERVICE}

1996-Present

Nursing

May 1995

1979-1987
Undergraduate Curriculum Committee, WVU School of

Presented program entitled "Breast Feeding: An Update" in Camden-on-Gauley, WV

Frequent Speaker on the Following Topics:

"Childhood Leukemia "

"Solid Tumors in Children"

"Nursing Children with Cancer"

"Hearthstone Children's House"

"When Your Student Has Cancer"

"Death and Children"

UPDATED: December 1, 2000 